\title{
ESTILOS DE GESTIÓN DE LOS PERFILES POLÍTICOS EN TWITTER: IMAGEN Y TEXTO EN LAS CUENTAS DE LOS PARTIDOS EN LA CAMPAÑA DEL 26J
}

\author{
Beatriz Gallardo Paúls \\ UNIVERSITAT DE VALÈnCIA \\ beatriz.gallardo@uv.es \\ Salvador Enguix Oliver \\ UNIVERSITAT DE VALÈNCIA \\ salvador.enguix@uv.es \\ Joan M. Oleague Moreno \\ UNIVERSIDAd INTERNACIONAL DE VALENCIA \\ juanmanuel.oleaque@campusviu.es
}

\begin{abstract}
Resumen: En este trabajo analizamos dos aspectos de las cuentas de los partidos políticos en Twitter durante la campaña del 26J: la estructura semiótica de los tuits y su función comunicativa. El análisis de estas dos variables permite concluir que 1) las cuentas de los partidos carecen en general de voz institucional y tienen sobre todo carácter ecoico respecto a las cuentas de los líderes, especialmente los candidatos; 2) existe equilibrio entre el uso de texto e imagen; 3) la función predominante es el tuit de cita; 4) las cuentas son uniformes, solo destaca la de IZQUIERDA UNIDA por su alto índice de espectacularización de la política. No hay, en definitiva, un estilo de gestión específico para la comunicación del partido en la red social.
\end{abstract}

Palabras Clave: análisis del discurso político; Twitter; semiótica.
Summary: Two aspects of the accounts of political parties on Twitter during the 26J campaign are analyzed: the semiotic structure of the tweets and its communicative function. The analysis of these two variables allows to conclude that 1) the accounts of the parties lack in general of an institutional voice, and have an echoic character over the accounts of the leaders, especially the candidates; 2) there is a balance between the use of text and image; 3 ) the predominant function is the quote tweet; 4) the accounts are uniform, only highlights IZQUIERDA UNIDA for its high rate of spectacularization of politics. In short, there is not a specific management style for the party's communication in the social network.

Keywords: political discourse anlysis; Twitter; semiotics. 


\section{PLANTEAMIENTO}

Este trabajo se integra en un proyecto amplio ${ }^{1}$ referido a cómo se construye discursivamente la subjetividad política en la red social Twitter, objetivo para el que se analizan muestras de datos pertenecientes a partidos y líderes políticos, a medios de comunicación, y a ciudadanos anónimos. En este trabajo concreto presentamos los resultados de un aspecto parcial del proyecto, que se refiere al análisis de la estructura semiótica de los mensajes publicados por los partidos políticos.

La irrupción de las redes sociales en el espacio comunicativo público a principios del s. XXI ha supuesto una verdadera revolución que, en el ámbito político, ha afectado a todos los actores. La comunicación política, al igual que el periodismo político, ha acogido este nuevo canal con verdadero entusiasmo (Abejón et al. 2017, hablan de "deslumbramiento"), concibiéndolo como un medio privilegiado que facilitaba la desintermediación, esto es, el acceso directo a los votantes sin necesitar el filtro de los medios (Castells 2008²). La sofisticación progresiva de las campañas electorales digitales ha supuesto la emergencia de "una nueva configuración comunicacional, radicalmente transformadora" (Dader 2017: 13ss), que en ciertos aspectos ha conseguido superar la centralidad estratégica del marketing político tradicional. De tal manera que la gestión comunicativa de la campaña digital, y muy especialmente la gestión de las redes sociales, se convierte en piedra angular de los procesos discursivos electorales. Las elecciones estadounidenses y francesas de 2016 y 2017 han puesto en evidencia el enorme poder que han conseguido las plataformas de redes sociales, para las que cabe proponer (Enguix 2017) un verdadero estatus de actor político.

En este ámbito, y frente a creencias tópicas bastante ingenuas que todavía hoy asumen que el uso de las redes sociales es una tarea poco especializada y de fácil desarrollo, estudios sistemáticos (Kreiss 2012) sobre la campaña de Obama de 2011 12 han demostrado que sus éxitos de movilización respondían "a la planificación meticulosa de innovadores equipos de especialistas, pertrechados con los más sofisticados avances en el almacenamiento y cruce de datos y nuevos métodos de investigación social que facilitan las crecientes mejoras tecnológicas e informáticas de la última década"

${ }^{1}$ Proyecto PRODIS-NET: Procesos discursivos en internet: confluencia de partidos, medios y ciudadanos, Ref. FFI2015-67668-R, MINECO/FEDER.

2 "La emergencia de la autocomunicación de masas desintermedia a los medios y abre el abanico de influencias en el campo de la comunicación, permitiendo una mayor intervención de los ciudadanos, lo cual ayuda a los movimientos sociales y a las políticas alternativas". 
(Dader 2017:15).

Junto a esta especial habilidad tecnológica, sin embargo, resulta imprescindible una habilidad discursiva, referida a la presentación y el encuadre informativo/cognitivo (Lakoff 2004, 2006; Gallardo 2014) de los mensajes en la red. Como ocurre en muchos otros ámbitos (la innovación educativa como ejemplo), la complejidad tecnológica e informática de las cuentas de los perfiles políticos en las redes sociales no puede suponer un fin en sí mismo, sino que está siempre al servicio del discurso que se difunde, lo que impone una profesionalización doble del gestor de redes sociales, digital pero también discursiva.

Desde este planteamiento, en este trabajo nos interrogamos sobre ese posible uso especializado en los perfiles de los partidos políticos en Twitter, analizando la estructura semiótica y pragmática de los tuits publicados por las cuentas de PP, Ciudadanos, PODEMOS, PSOE e IU en la precampaña de las elecciones generales del 26 de junio de 2016. Las cuestiones que nos planteamos son:

- ¿Cuál es la estructura semiótica de los tuits publicados por las cuentas de los partidos? ¿Hasta qué punto asumen la necesidad de imagen y video?

- ¿Cómo se combina el uso de texto e imagen?

- ¿Hasta qué punto las cuentas de los partidos desarrollan un discurso propio, y de qué naturaleza es ese discurso?

\section{LOS DATOS}

Presentamos los resultados de una muestra de tuits obtenida a partir de la aplicación TwitDocs; la exportación se realizó el 14 de junio de 2016, y cubría los últimos 3200 tuits de cada cuenta, extendiéndose en las fechas que se señalan en la Tabla 1. Como puede verse en la Tabla 1, la descarga exacta no siempre es de 3200 tuits. Puesto que el interés de este trabajo es estrictamente semiótico, y no tiene en cuenta los aspectos semánticos e ideológicos del mensaje ni el análisis del contenido, mantenemos el análisis de todos los tuits de cada cuenta analizada, sin igualar las cinco submuestras según las fechas de publicación ${ }^{3}$.

${ }^{3}$ En Gallardo (2016) se justifica por qué, a diferencia de múltiples estudios sobre comunicación política en Twitter, evitamos el uso de las etiquetas como pauta para configurar el corpus. Aunque las etiquetas son mecanismos evidentes del encuadre temático de los tuits, lo cierto es que su uso es cada vez menor, y utilizarlas como criterio selectivo lleva a excluir de la muestra muchos mensajes. El criterio cronológico de una app como TwDocs (también aplicable en la descarga mediante Python que utilizamos en otros trabajos del proyecto PRODISNET) ofrece muestreos completos para períodos temporales. 
Los datos de la Tabla 1 nos indican una actividad diferente de las cuentas en la red social, con un ritmo de publicación que, si la calculamos para días completos, se mueve entre 66 tuits diarios en el PP y 217 en la cuenta del PSOE 4 .

\begin{tabular}{|l|l|l|}
\hline \multicolumn{1}{|c|}{$\begin{array}{c}\text { PARTIDO } \\
\text { (NUM DE TUITS) }\end{array}$} & \multicolumn{1}{c|}{ INICIO } & \multicolumn{1}{c|}{ FINAL } \\
\hline CIUDADANOS (3192) & 6 de mayo de 2016 & 14 de junio de 2016 \\
\hline IU (3200) & 20 de mayo de 2016 & 14 de junio de 2016 \\
\hline PODEMOS (3199) & 19 de mayo de 2016 & 14 de junio de 2016 \\
\hline PP (3200) & 27 de abril de 2016 & 14 de junio de 2016 \\
\hline PSOE (3193) & 30 de mayo de 2016 & 14 de junio de 2016 \\
\hline
\end{tabular}

Tabla 1: Detalles de los datos del corpus analizado.

Por tanto, el corpus global utilizado para este trabajo utiliza todos los tuits obtenidos el 14 de junio sin atender a la fecha de publicación, por lo que la muestra es de 15.984 tuits pertenecientes a los perfiles de partidos políticos más relevantes en el panorama electoral del momento.

\section{LAS CATEGORÍAS Y EL ANÁLISIS DEL CORPUS}

Presentamos un modelo de análisis de los tuits de elaboración propia, que contempla 4 posibilidades en la estructura del tuit, codificadas de la siguiente manera:

1. Texto: el tuit solo incorpora texto escrito (se han incluido en esta categoría 13 tuits cuyo texto estaba formado íntegramente por emoticonos).

2. Texto + video: texto acompañado de vídeo.

3. Texto + infografía, Texto + fotografía, Texto + diapositiva: texto

${ }^{4}$ Si comparamos estas cifras con la actividad de las cuentas personales de los políticos (Gallardo 2018) vemos unas tasas de actividad muy diferentes, que en los días del intento de investidura de Pedro Sánchez en marzo de 2016 oscilan entre los 7 tuits diarios del perfil de Iglesias y los 25 mensajes diarios de Rivera (seguido muy de cerca por Garzón con 24,3 tuits por día). Como vemos en este trabajo, las cuentas de los partidos tienen como función básica la dispersión de estos mensajes procedentes de las cuentas personales. 
acompañado de una imagen fija, que puede ser de tres tipos básicos: infografía, fotografía y diapositiva/cartel.

4. Texto + url: texto y enlace, que puede ser texto exclusivamente o desplegar imagen o vídeo contenido en el hipervínculo.

Como hemos indicado, esta clasificación de punto de partida obedece a criterios estrictamente semióticos, tal y como ocurre en otras propuestas. Por ejemplo, García-Avilés y Arias (2016) han formulado una clasificación para tuits periodísticos con imagen que, dentro de las cuatro opciones semióticas básicas (vídeo, imagen, infografía y GIF) atiende a diferencias entre géneros textuales; la tipología, sin embargo, es tan amplia que pierde operatividad y se queda en el nivel meramente descriptivo:

1. Representaciones gráficas: géneros informativos (fotonoticia, fotogalería, última hora, exclusiva, datos clave, documento, narración en directo, portada, revista de prensa, cabecera, recorte, datos en bruto, nube de etiquetas, cronología), géneros interpretativos (meme, mapa conceptual, homeaje, ilustración explicativa, ilustración perfil, viñeta, imagen retocada, making of, perfil), géneros argumentativos (columna, editorial, comentario), géneros dialógicos (foto-declaración, extracto de entrevista, cita de tuit, encuesta, encuentro, quiz). 2. Infografías (ubicativa, estadística comparativa, estadística ubicativa, diagrama, diagrama ubicativo, esquema, multigráfico).

3. Vídeos: géneros referenciales (noticia, última hora, reportaje, informe, obituario, revista de prensa, teaser, making of, videográfico diagrama, videográfico organigrama, videográfico estadístico, video multigráfico), géneros testimoniales (editorial, análisis, comentario, crónica), géneros dialógicos (entrevista, entrevista ilustrada, conexión con corresponsal, declaración, vox populis, encuentro, rueda de prensa, reclamo).

4. GIFs: géneros referenciales (noticia, titulares, informe, reportaje, cronología, ilustrativo, didáctico, teaser), géneros infográficos (diagrama, organigrama, ubicativo, cronológico, combinado, estadístico comparativo).

El análisis global del corpus de los cinco partidos nos ofrece que el $41,1 \%$ de los tuits son exclusivamente mensajes de texto, mientras los demás tuits incluyen algún tipo de imagen. Si atendemos a la diferenciación por partidos, nuestra clasificación en cuatro tipos básicos de tuit proporciona los resultados del siguiente gráfico: 


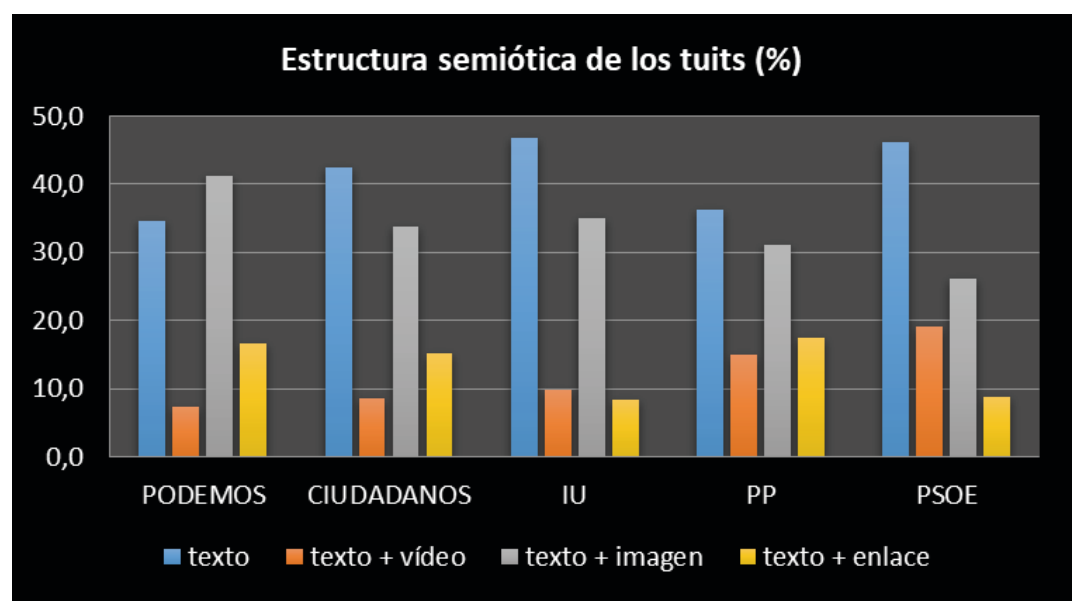

Gráfico 1: Resumen del análisis: estructura semiótica de los tuits según partidos.

La observación más inmediata del gráfico resultante del análisis inicial es que los tuits de solo texto mantienen el protagonismo global, si bien en la cuenta de PODEMOS son superados por los tuits de imagen fija. En todo caso, si sumamos los tuits que utilizan imagen (fija o móvil), el protagonismo del texto escrito desaparece y ambos tipos se equilibran, siendo mayoritarios los tuits que incluyen imagen en las cuentas del PP y PODEMOS:

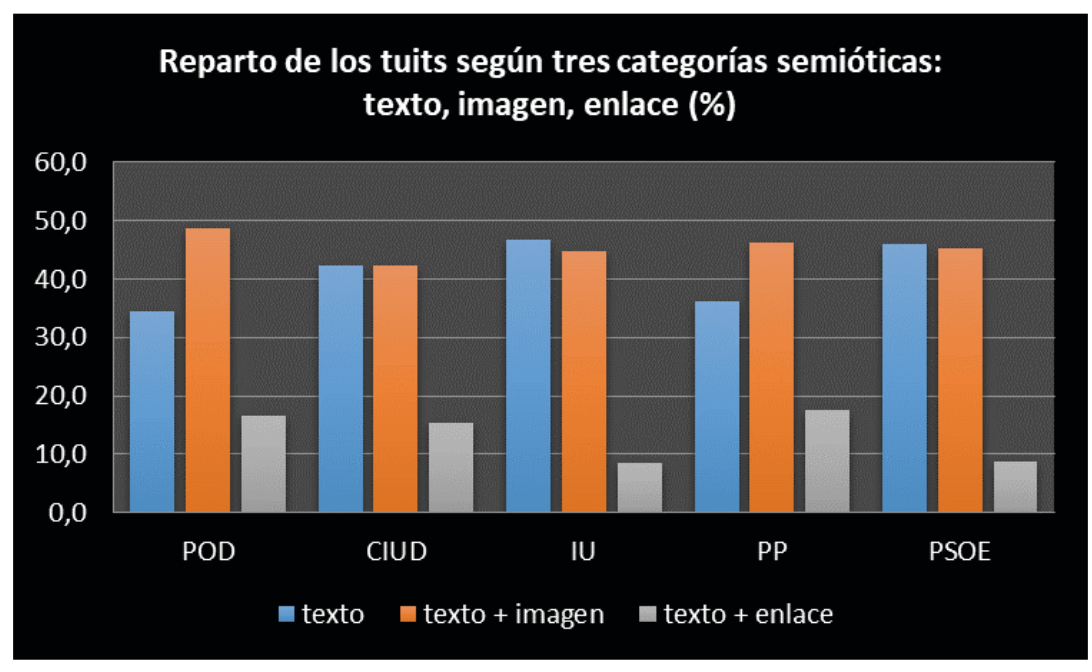

Gráfico 2: Equilibrio entre los mensajes de texto e imagen. 
Téngase en cuenta, además, que el gráfico 2 oculta el hecho de que los tuits que incluyen algún tipo de enlace a la red también pueden desplegar imágenes; el $58 \%$ de los tuits que enlazan a alguna página web incluyen a su vez algún contenido visual.

Por tanto, la primera conclusión del análisis semiótico de los tuits de los partidos políticos es la importancia de la imagen; en cifras globales, el corpus muestra un $54,5 \%$ de tuits de solo texto, y el $45,5 \%$ de tuits con algún tipo de apoyo visual. A continuación desarrollamos un análisis más detenido de la estructura y las funciones de texto e imagen.

\subsection{La funcionalidad de los tuits: imagen y texto al servicio de los líderes}

Independientemente de la estructura semiótica de los tuits, si atendemos a la función de los mensajes que se publican en cada perfil de partido vemos que existen tres tipos básicos de tuit: los tuits de cita, los tuits de agenda y los tuits de la voz del partido, a los que se suman otras acciones menos específicas.

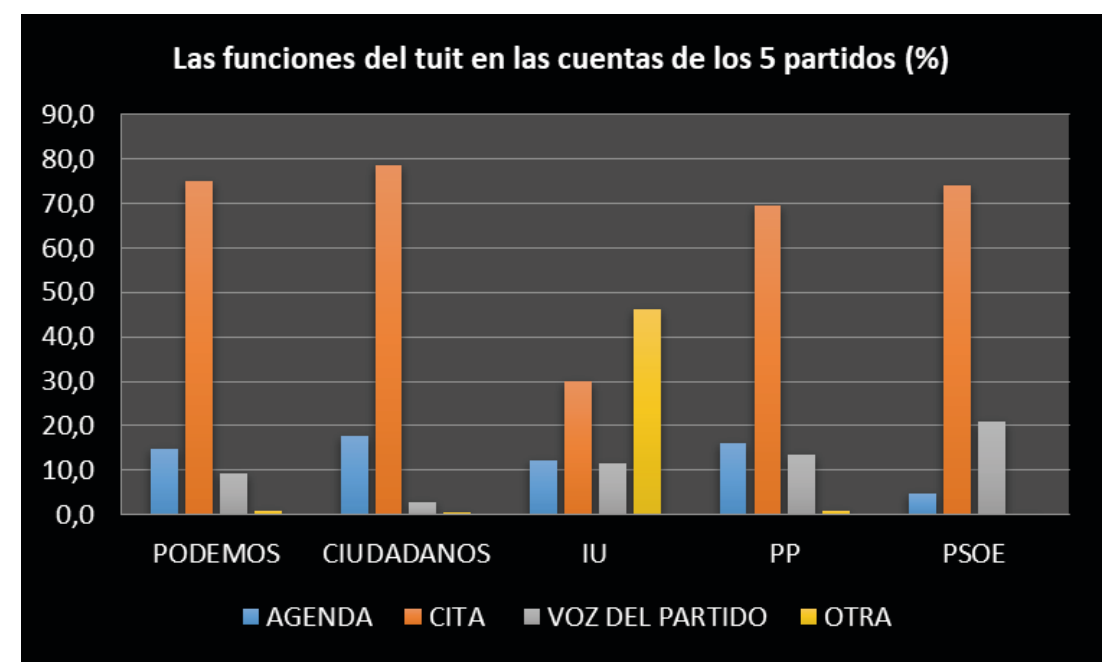

Gráfico 3: Asignación de funciones a los tuits que se publican en las cinco cuentas (sin los retuits).

Todas las cuentas salvo la de IU dan protagonismo absoluto a la voz de sus líderes con los que hemos llamado tuits de cita, reproduciendo fragmentos de lo que dicen en sus actos públicos. Como refleja el gráfico, esta es la actividad central de 
estas cuentas de partido, que en la mayoría de ocasiones filtran su voz por la voz de los líderes, contribuyendo decisivamente al personalismo de la política. Estos tuits de cita se apoyan en la imagen, que puede tener un contenido coincidente (la foto o el vídeo ilustra exactamente las palabras citadas) o bien complementario (cuando el recurso visual introduce otra información que amplía la contenida en el texto). PODEMOS, CIUDADANOS y PSOE dedican a esta función más del $74 \%$ de sus tuits propios.

Los tuits de agenda son el segundo gran grupo de tuits. Presentan una función metacomunicativa que se presenta con diversos formatos; puede ser tanto un acto directivo que emplaza a los seguidores/votantes a determinado acto (" $i$ Te esperamos!”, “ ¡No te lo pierdas!”), como una entrevista a los líderes, un acto de campaña, una petición del partido. En otras ocasiones estos tuits de agenda toman un formato más informativo, con actos de habla representativos que presentan y contextualizan el contenido visual que se tuitea o se va a tuitear. Normalmente estos mensajes se acompañan de algún reclamo visual. Todas las cuentas utilizan estos tuits de agenda, que describen la actividad prevista a diario para sus líderes y sus apariciones en medios de comunicación; destaca por su mínima utilización la cuenta del PSOE, que solo dedica a la función de agenda el 4,9\% de los tuits propios.

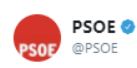

Sigue en directo las declaraciones de @AmbBatet en la sede del PSC a partir de las 11h. ¡No te lo pierdas!

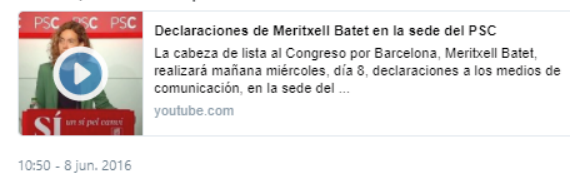

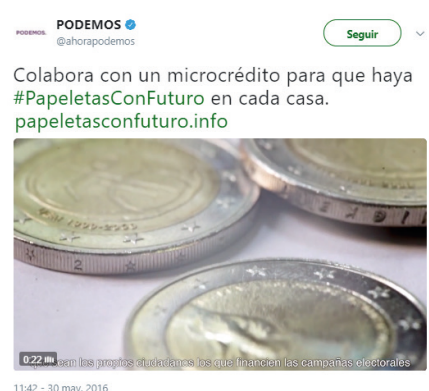

$11: 42-30$ may. 2016

Imagen 1-2: Ejemplos de tuits con función directiva, de agenda: emplazamiento a un evento politico futuro.

En tercer lugar, los tuits que introducen la voz del partido son los que hablan de medidas políticas sin vincularlas explícitamente a las declaraciones de sus líderes; son claramente el grupo menos numeroso, lo que parece indicar que las cuentas no están siendo gestionadas realmente como perfiles de partido, sino por personal de apoyo que no tiene capacidad/autoridad para asumir la voz del partido, y al que no se proporcionan estos contenidos; este es claramente el punto débil de la comunicación partidista en Twitter. Además, muchos de estos mensajes — cuya función hemos establecido a partir del texto de los tuits-, se completan con imágenes de 
los líderes, lo que de nuevo insiste en el factor de personalismo. El PSOE (21\%) es el partido que más recurre a este tipo de tuits generalistas, ideológicos, vinculados a la exposición del programa electoral.

Por último, una parte mínima de los tuits propios se utilizan con otras funciones, aspecto en el que destaca sobre todo el perfil de IU, con un $46,3 \%$ de tuits propios con estas funciones diferentes; la más habitual es la publicación de tuits reactivos, que dialogan brevemente con los seguidores; también vemos muchos mensajes autorreferenciales que hablan de la actividad de gestionar la cuenta, o se dedican a un tipo de crítica burlona y satírica que podemos considerar como tuits de expresividad negativa.

Esta descripción funcionalista de los tuits publicados por los partidos se completa con los retuits que publica cada cuenta. Como refleja el gráfico 4, el PP es el partido que más retuitea y PODEMOS el que menos. Los tuits redifundidos por las cuentas de los partidos suelen ser fundamentalmente de las cuentas de sus líderes - lo que vuelve a insistir en la función de cita-, y tuits de medios de comunicación donde se habla de los líderes y sus apariciones — rara vez tuits que hablan de los partidos como entidades-. El retuit de las cuentas del candidato es máximo en la cuenta del PP y de Ciudadanos, mientras que las cuentas de PSOE, IU e Iglesias no dan el mismo protagonismo a los tuits del candidato (3,3\% de los retuits de IU son de Garzón; 5,5\% de retuits de Iglesias en el caso de PODEMOS; y $8 \%$ de los retuits del PSOE son de Sánchez).

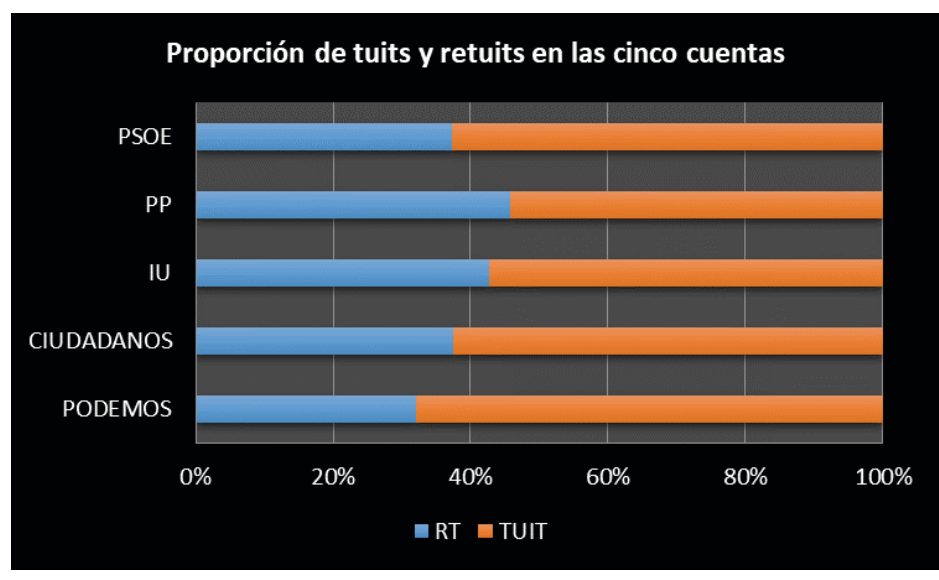

Gráfico 4: Proporción de tuits y retuits en las cinco cuentas. 


\subsection{Los tuits de texto simple}

Pese a la innegable función de captatio que tiene la imagen (Pratkanis \& Aronson 1992), gran parte de los tuits publicados desde las cuentas de los partidos están formados por texto escrito, sin apoyo visual de ningún tipo. Todos los partidos dedican la gran mayoría de estos tuits de texto a reproducir citas de sus respectivos líderes políticos, en una proporción que supera el 91\%, con la excepción de la cuenta de IU, donde el uso del tuit de texto para la cita de líderes es minoritario (predomina la función reactiva y de complicidad con el seguidor).

En la cuenta de Ciudadanos, la estructura habitual del tuit de cita va precedida del alias del político citado, seguido del mensaje entre comillas, y opcionalmente alguna alusión al contexto institucional o mediático en el que se pronuncia el mensaje. Aunque el perfil de IU recurre menos a los tuits de cita, mantienen el uso de las comillas, lo mismo que en el caso de PODEMOS, que también menciona al autor de las citas con su alias de Twitter. En los casos de PP y PSOE, el uso de las comillas es ocasional, y predomina la cita directa y la mención del político al que se cita (salvo unos pocos casos sin cuenta en la red), indistintamente al principio o al final del texto.
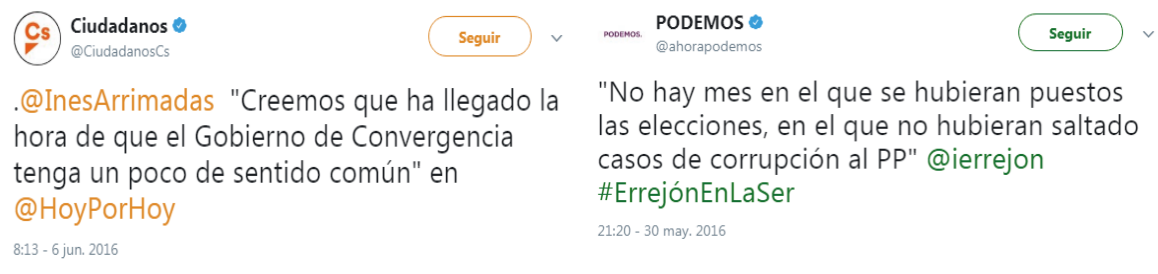

"No hay mes en el que se hubieran puestos las elecciones, en el que no hubieran saltado casos de corrupción al PP" @ierrejon \#ErrejónEnLaSer 21:20 - 30 may. 2016

\section{PP Partido Popular $=$}

Aquí hay que venir ya llorado de casa: una cosa es estar detrás de la pancarta y otra tomar decisiones@isabelbonig \#BuenGobierno 11:46 - 19 may. 2016

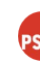
@sanchezcastejon pertenece a una gran
familia que defiende un país con justicia,
libertad e igualdad. @susanadiaz
\#EPDesayunosSánchez
9:22-7 jun.2016

Imagen 4-6: Presentación típica de los tuits de texto en las cuentas donde la función de cita es predominante.

La cuenta del PSOE es la que dedica más tuits a introducir la que hemos categorizado como "la voz del partido", normalmente con actos de habla compromisorios que se dedican a difundir el programa electoral: 


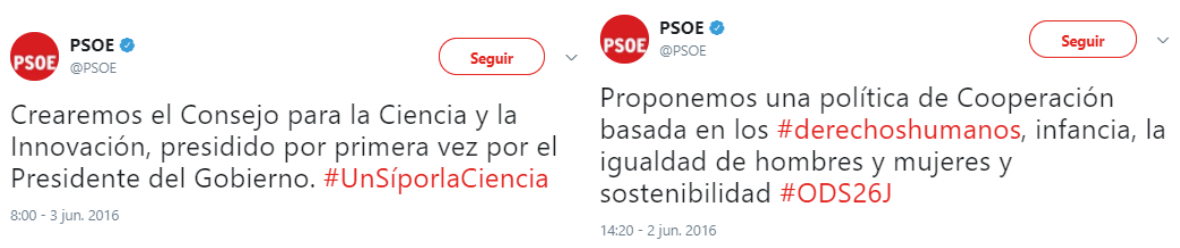

Imagen 7-8: Tuits textuales del PSOE que introducen la voz del partido.

\subsection{Los tuits con imagen: fotografía}

En la dimensión textual del encuadre informativo (Gallardo 2017), la estrategia paratextual se apoya en la materialidad del discurso, mediante la gestión de los aspectos sonoros (prosodia, música) o visuales, como la imagen, el estilo, tamaño y tipo de letra, etc. La imagen incluida en los tuits puede ser una imagen fija, para la que establecemos tres subtipos, o bien una imagen animada, ya sea GIF o vídeo. Contrariamente a lo que ocurre con la escritura, apenas aparecen tuits que estén formados exclusivamente por una imagen, y en tales casos $(\mathrm{N}=2)$ se trata de imágenes/ cartel, cuya composición incluye un apoyo de texto incrustado en la imagen, por mínimo que sea, o bien unos cuantos mensajes $(\mathrm{N}=13)$ integrados exclusivamente por uno o más emoticonos, y que hemos computado como tuits de texto escrito debido a que son imágenes proporcionadas desde el mismo teclado de la escritura. Por tanto, la gestión de las cuentas de Twitter por parte de los partidos da importancia a la imagen, pero la encuadra siempre de algún modo mediante texto; la red social se utiliza con la intención de transmitir mensajes específicos, que no se confían completamente a la capacidad interpretativa del receptor, sino que su lectura se orienta explícitamente.
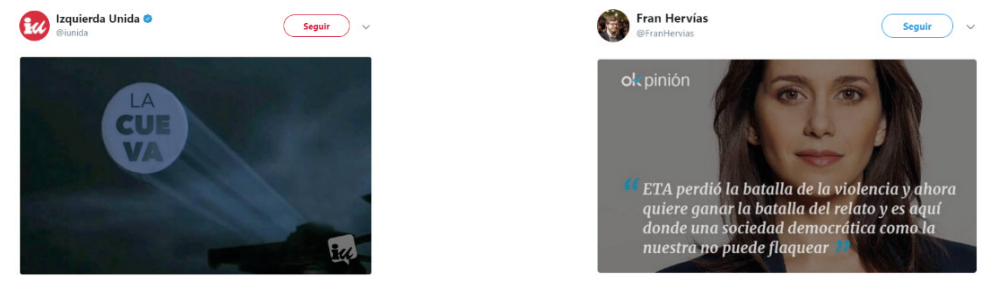

Imagen 9-10: Dos casos extremos de tuit sin apoyo textual: un cartel de IU autorreferencial ("La cueva" fue el nombre que designaba al equipo de redes sociales durante la campaña) y un retuit de CIUDADANOS de una cuenta de medio de comunicación, cuya composición integra texto (cita) y rostro de representante politico. 
Aunque las primeras webs de los partidos políticos tardaron en introducir los recursos multimedia (Auty y Cowen 2001), la utilización de la imagen ha ido creciendo progresivamente en las redes sociales, y las cuentas de los partidos políticos participan de esta tendencia: "se observa que cada vez es más recurrente el empleo de imágenes durante los eventos de mayor calado político, para conseguir atraer a nuevos seguidores o criticar y polemizar a los rivales politicos" (Ruíz del Olmo y Bustos 2016: 113). Los medios han contribuido sin duda a imponer esta tendencia (López-Rabadán et al. 2016), y estos a su vez se han visto presionados por la idea, difundida por los gestores de las plataformas de redes sociales, sobre todo Facebook (Enguix 2017), de que el usuario se detiene más en las publicaciones con vídeo y fotografía.

La imagen del político es, obviamente, la tarjeta de presentación del partido (Castells 2008; Marland 2012). La conversión del líder político en "marca" (Neddham 2005) es un fenómeno que, desde el punto de vista teórico, se vincula a muchos rasgos de la comunicación política del siglo XX, como la narrativización espectacularizante de los medios de comunicación (Johnson-Cartee 2004), por ejemplo, o la campaña permanente (Blumenthal 1980). López-Rabadán et al. (2016) comprueban que el protagonismo de la fotografía se da en un 30\% de los mensajes de los partidos políticos (análisis de tuits referidos al último trimestre de 2015), y que en ese predominio de la imagen destaca la fotografía del político como protagonista de la acción política (lo que en términos discursivos se corresponde con la estrategia predicativa del encuadre, es decir, al quién de la política; Gallardo 2014, 2016, 2017). En el global de nuestros datos, los tuits con fotografía (es decir, exlcuyendo videos e infografías-carteles) son un $28,2 \%$ de la muestra, y también predomina absolutamente la fotografía de los líderes internos.

Usher señala (2016: 20) que el análisis de las imágenes difundidas en redes durante la campaña electoral "offers a focused timeframe to examine how persona is constructed and managed through the capture of real-life 'experiences' (such as on the campaign trail), displays of agreement with the electorate and the purposeful use of other discourses, such as journalistic coverage or manifesto pledges". Usher enfoca las imágenes de los políticos en sus perfiles de redes sociales como elementos de contrucción de microcelebridades: "Microcelebrity, in this context, is therefore understood as a production mechanism through which politicians can build a following, enabling them to extend their message and reach members of the electorate who may not engage with mainstream representational media" (2016: 21). Esta autora analiza cómo la difusión de las imágenes (tanto en los "me gusta" como en la redifusión de los seguidores) ayuda a crear y mantener la visibilidad de los líderes políticos.

Para los casos de imagen fija, nuestros datos nos permiten identificar tres tipos básicos de publicaciones: 
1. Texto y fotografía, es decir, imagen tomada en directo y compartida en la red social. Predomina en todos los partidos la fotografía del líder interno (Lópz Rabadán et al. 2016: 174).

2. Texto e imagen editada, es decir, que implica algún tipo de elaboración para añadir información; son en general elaboraciones bastante simples que evocan la edición mediante algún programa de presentaciones tipo Power Point.

3. Texto e infografía, es decir, imagen construida pero sin apoyo fotográfico.

Entre todos los tuits que publican texto e imagen fija, los tuits con fotografía son los tuits más habituales para las cinco cuentas, con valores que están entre el 47,5\% del PSOE y el 78,1\% de Ciudadanos. En el corpus global, el partido que más utiliza los tuits de texto con fotografía es PODEMOS.

No obstante, si atendemos a la especialización semiótica de los tuits según su función comunicativa, observamos algunas diferencias. PODEMOS e IU utilizan predominantemente la fotografía, para cualquier tipo de tuit. CIUDADANOS da prioridad a la fotografía para los tuits de agenda y de cita, pero para introducir la voz del partido se apoya más en infografías ${ }^{5}$. El PP prefiere la infografía para los tuits de cita, pero recurre más a la fotografía editada en las funciones de agenda y de voz del partido. Por último, el PSOE apuesta por las infografías tanto para introducir la voz del partido como para ilustrar los tuits de cita, mientras que para la agenda utiliza sobre todo fotografías editadas. A continuación revisamos por separado las cuentas de los cinco partidos.

La mayoría de las fotos de la cuenta de PODEMOS son fotos de sus líderes participando en distintos actos, como mítines, comparecencias ante los medios, selfies con los voluntarios, fotos en el plató de televisión, o fotos panorámicas donde se subraya el éxito de convocatoria; los textos ofrecen la información de contexto en cada caso. Predomina la naturalidad de la foto testimonial, el directo. Twitter se usa como medio de retransmisión de la actividad de los líderes, y se publican extractos de lo que dicen Errejón, Montero, Iglesias, Echenique, Espinar, etc., acompañando esos extractos con fotos simultáneas. Este factor de simultaneidad, de "retransmisión en directo" es claramente mayoritario, ya sean fotografías del acto del que se informa, ya sean fotografías de pantallazos o recortes en los que el político aparece en una tertulia, en una entrevista, etc.

Aparte, hay también algunas fotos que corresponden a líderes de otros partidos, pero estas ya no son fotos tomadas in situ, sino normalmente procedentes de

${ }^{5}$ Este es un recurso que este partido explotó especialmente en los días de la investidura fallida de Pedro Sánchez, para presentar los contenidos del pacto PSOE-CIUDADANOS. 
medios de comunicación, y lo normal es que se acompañen de textos de crítica. Por último, hay también algunas fotos de "pruebas documentales": recortes de textos publicados en prensa (comentados críticamente en el texto), foto del billete de tren que demuestra la falsedad de una noticia sobre viaje en primera clase, recorte de un fragmento del programa electoral, de un comunicado sobre cierta candidatura, etc.
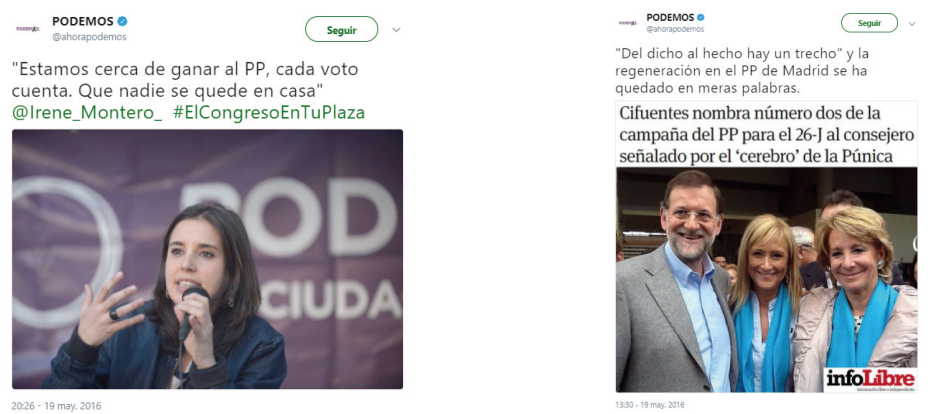

Imagen 11-12: Fotografias en PODEMOS: las fotos de los lideres del partido son fotos "directas", que son tomadas en el momento; las fotos ocasionales de los lideres de otros partidos suelen ser fotos "diferidas", tomadas de los medios. Tuit de retransmisión vs. Tuit de comentario.

Las fotos de CIUDADANOS dan también absoluto protagonismo a sus líderes. Observamos el recurso a fotos de archivo sobre todo en los tuits de agenda previos al acto en cuestión, o en tuits referidos a personas que no son del partido; en estos casos es la imagen la que acompaña el texto, pero sin la relevancia informativa de los casos de "imagen en directo”. Las fotografías de los líderes se acompañan de otras fotos "de detalle" que muestran el lugar preparado para el acto en los momentos previos.
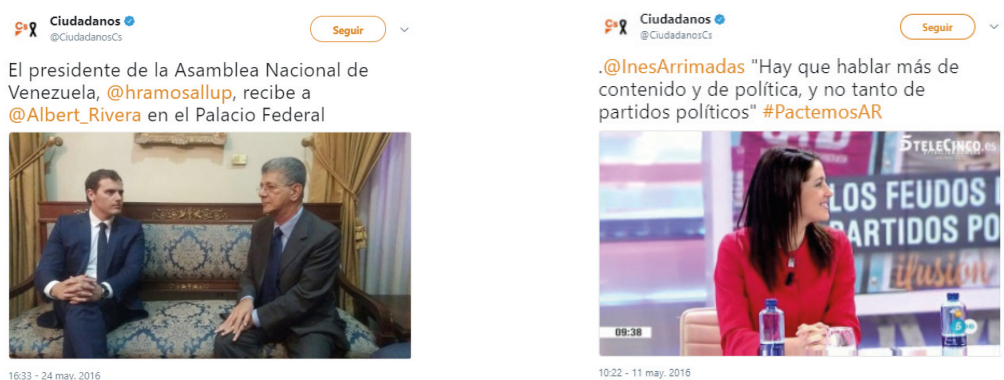

Imagen 13-14: Fotos de simultaneidad en Ciudadanos: foto del lider tomada en el acto que se comunica, ofotograma de una aparición en medios. 
Por lo que se refiere a la cuenta de IU, una de sus peculiaridades es que, sin abandonar el protagonismo absoluto de Alberto Garzón, las fotografías de líderes en los distintos actos retransmitidos componen el panorama más coral de todos, especialmente por la inclusión de múltiples fotografías pertenecientes a la Asamblea de IZQUIERDA UNIDA en las que se incluyen múltiples miembros del partido y líderes invitados de otras formaciones nacionales e internacionales. Por supuesto, colabora a esta situación de protagonismo coral el hecho de que IU se presentara a la cita electoral en coalición con otras formaciones, como PODEMOS, COMPROMÍS O EN COMÚ, si bien en el perfil de PODEMOS el protagonismo de sus líderes es bastante más rotundo y no se percibe esta misma apertura a un protagonismo compartido. Igualmente, son mucho más frecuentes que en el resto de cuentas las fotos de panorámica o con simpatizantes, que inciden en el éxito de convocatoria y participación. Ese protagonismo compartido coincide con el análisis de las fotos de Instagram (Gallardo y Enguix 2016, 2017).
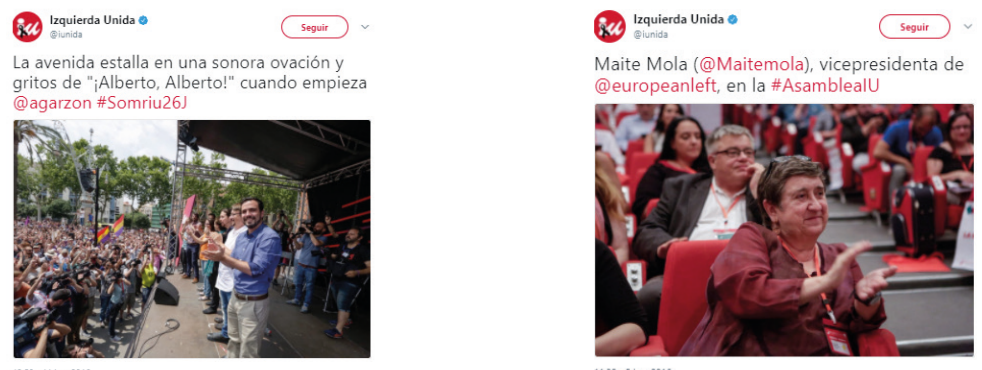

Imagen 15-16: Fotos de líderes en IZQUIERDA UNIDA: el indiscutible protagonismo de Alberto Garzón se combina con un protagonismo coral de líderes de otras formaciones.

Como ya se ha dicho, el perfil de IU destaca por el protagonismo que asume el propio equipo gestor de la cuenta, y esto se manifiesta también en los tuits que incorporan fotografía, si bien el protagonismo es también grupal y despersonalizado:
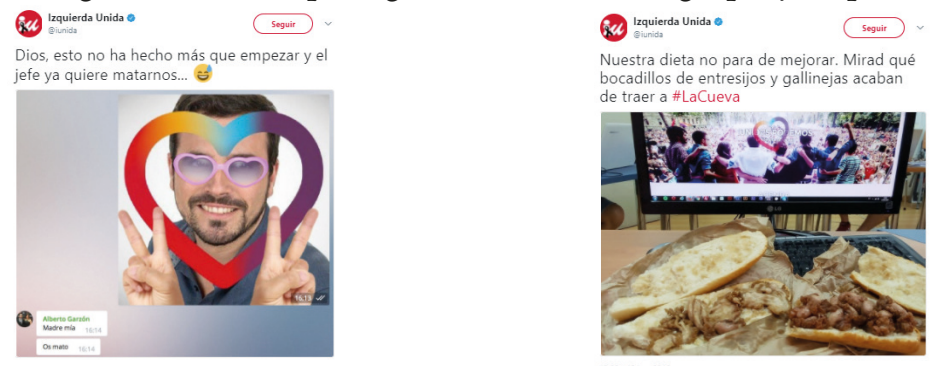

Imagen 17-18: Fotos en IZQUIERDA UNIDA: el protagonismo del tono burlón de los gestores de la cuenta funciona como elemento que apela a la identificación con el seguidor, es decir, la creación de comunidad. 
E igual que ocurría con los tuits de texto, en los tuits de imagen la cuenta de IU destaca por la frecuencia de tuits dedicados totalmente a la espectacularización y el enfoque frívolo, con un humor que se mueve en el espectro que va del juego lúdico al sarcasmo, que busca la complicidad emocional pero que a veces (Gallardo 2017) provoca comentarios de rechazo por parte de algunos seguidores.

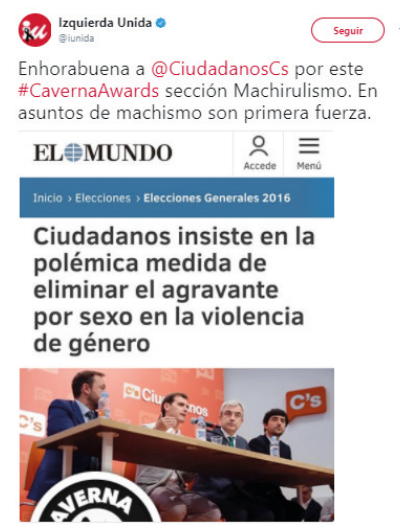

Imagen 19-20: La espectacularización de la politica en los tuits de IZQUIERDA UNIDA: convertir en competición de premios el tema del machismo, animar a los seguidores a hacerse eco de la campaña en sus propios perfiles.

El perfil de PARTIDO POPULAR publica casi un tercio de sus tuits con alguna imagen, y más de la mitad de ellos son tuits de texto con fotografía. Como en el resto de cuentas, el protagonismo absoluto de las fotos lo tiene el candidato, Mariano Rajoy. Un recurso frecuente para las fotografías que muestran al líder en cierto acto es añadir el enlace a la web del partido (www.pp.es) aludiendo a su posible seguimiento en directo, pero sin proporcionar el enlace concreto del streaming. Lo que más destaca de las fotografías que muestran a los líderes del partido es el predominio de fotografías pertenecientes a intervenciones en programas de medios de comunicación, mientras en el resto de los partidos se aprecia equilibrio entre las fotos de medios y las fotos de otro tipo de acciones (mítines, reuniones, viajes, ruedas de prensa). Estas fotografías juegan con frecuencia a ofrecer encuadres triangulados, es decir, filman la cámara que filma al político, pero no llegan a ser las "fotos entre bambalinas" que a veces publican los políticos en sus cuentas personales (Gallardo y Enguix 2016). 

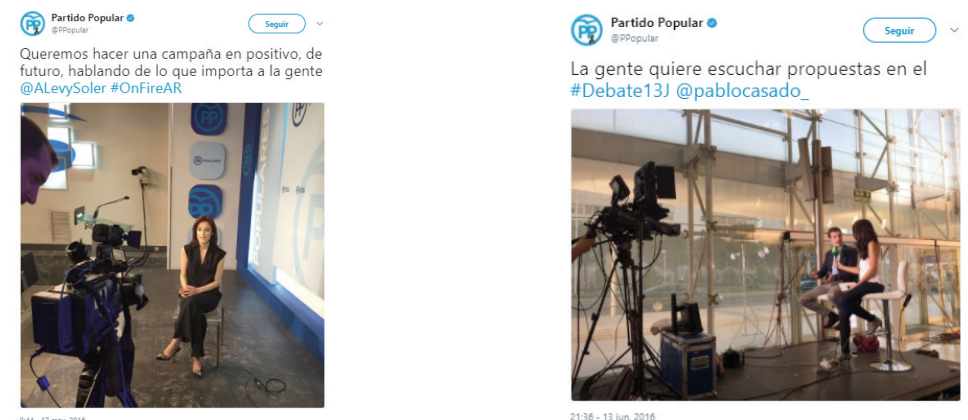

Imagen 21-22: Fotografias del PP: llama la atención el gusto por fotos de triangulación mostrado las cámaras, que insisten visualmente en el interés mediático que generan los líderes.

Por último, el del PSOE es el perfil que menos recurre a la imagen fija en sus tuits, pero en los casos en que lo hace, casi la mitad son fotografías que ilustran el evento del que habla el texto del tuit: el momento en que el líder político pronuncia cierta frase citada, el acto de partido que se enuncia o al que se da cobertura; son fotos de valor testimonial que insisten en el efecto de realidad de la retransmisión:
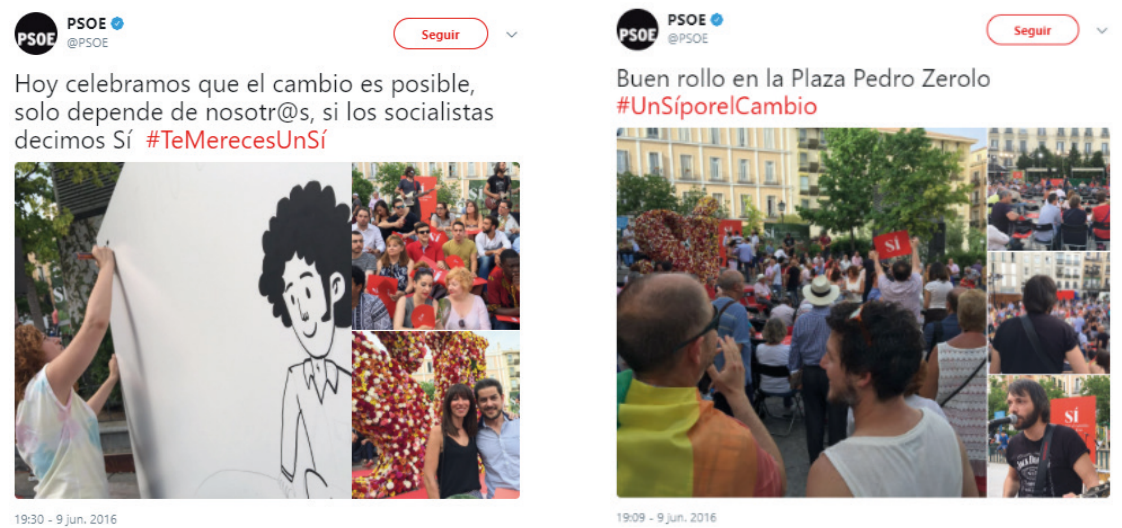

Imagen 23-24: Fotografías del perfil del PSOE, cobertura de un acto de partido de homenaje al politico del PSOE fallecido, Pedro Zerolo.

En definitiva, la fotografía más habitual de los tuits de todos los partidos es la que se ajusta al descriptor "líder en el acto", ya se trate de una fotografía tomada in situ o, cuando se trata de actos televisados, un pantallazo de esa retransmisión en directo. En estos casos, así como en otros menos frecuentes que fotografían "otros detalles del acto” (panorámica de asistentes, lugar preparado para el acto...), se 
puede afirmar que imagen y texto se complementan y la relevancia informativa de ambos recursos es equilibrada. Habida cuenta del factor de simultaneidad de estas fotografías respecto al momento de publicación (retransmisión), cabría pen$\operatorname{sar}^{6}$ que todas son hechas y publicadas mediante dispositivos móviles, aunque un análisis detenido ofrece diferencias de calidad entre las diferentes cuentas, tanto técnicas como de factura.

Usher (2016: 34) ha señalado cómo cualquier persona que se cruce con el político es un fotógrafo potencial, debido a la omnipresencia de los teléfonos móviles con cámara fotográfica; en este sentido cabría pensar que cuando los partidos difunden fotografías y vídeos tomados con estos dispositivos están promoviendo la identificación de ese ciudadano anónimo que se cruza con el político o que asiste a sus actos de campaña.

\subsection{La imagen editada: cartel e infografía}

Los tuits con imagen editada incluyen algún tipo de manipulación de la fotografía, por ejemplo añadiendo texto, o construyendo algún diseño a modo de anuncio del acto de partido, la comparecencia en medios, etc. En todo caso, son imágenes que, frente a la simultaneidad que permitía la fotografía aislada, exigen un tiempo de edición; muchas de estas imágenes utilizan claramente fotos de archivo para la composición, no son instantáneas tomadas en un acto sino fotos de estudio. Estos tuits muestran clara proximidad con el cartel electoral, y con frecuencia repiten su estructura típica de imagen del candidato y frase de eslogan. Junto a los carteles de agenda, que incluyen información sobre cuándo o dónde tendrá lugar cierto acto de interés, hay otras imágenes que superponen el texto pronunciado a la fotografía del emisor, y otras que siguen la lógica propagandística (Pratkanis \& Aronson 1992).

\footnotetext{
${ }^{6}$ Los intentos de acceder a información directa sobre la gestión de estas cuentas por parte de los dircom han sido infructuosos (Pellisser, Villar y Enguix 2017).
} 


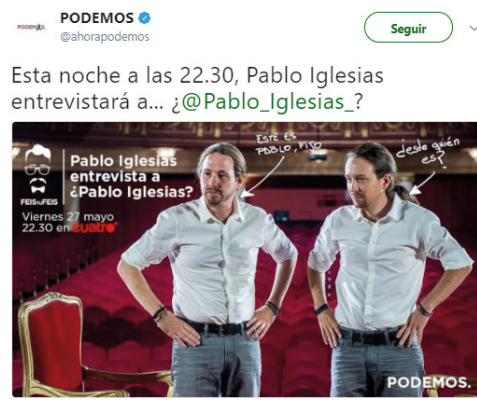

18:20 - 27 may. 2016

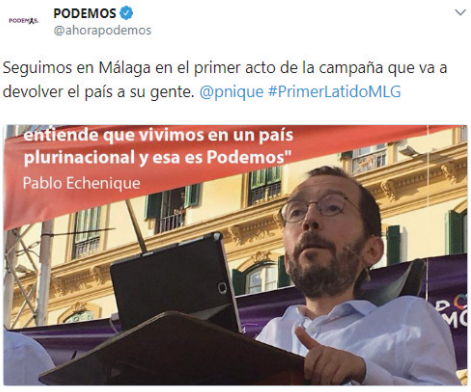

7:48 p. m. 10 jun. 2016

Imagen 25-26: Fotografia editada en los tuits de PODEMOS; tuit de agenda y tuit de cita.

Todo este material gráfico es dispar y muestra un nivel bajo de elaboración estética o conceptual, no se utiliza un criterio claro de imagen corporativa más allá de mantener esquemas repetitivos en la disposición de texto e imagen, o mantener una línea cromática constante; la estética imperante suele ser la clásica del cartel electoral, con el primer plano del candidato y el texto informativo. Por ejemplo, en los tuits que anuncian actos con participación de los líderes, el PP recurre a fotos de estudio poco naturales, y se mueve siempre en tonos azules con solo algún desliz a tonos verdes, manteniendo el formato y la tipografía.

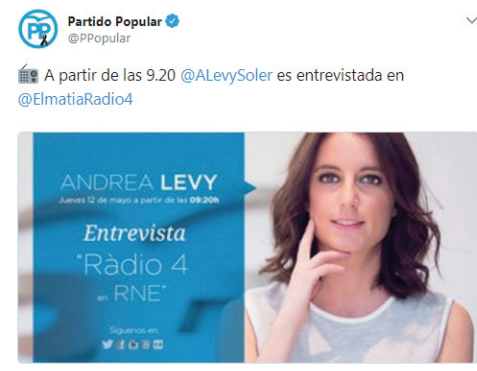

9:18 a. m. 12 may. 2016

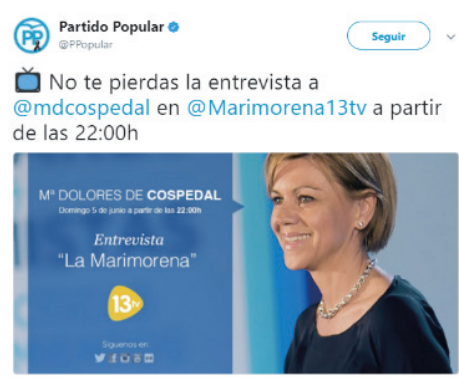

$20: 26-5$ jun. 2016

Imagen 27-28: Formato típico de los tuits de agenda en la cuenta del PP.

CIUDADANOS utiliza un formato reiterado de cartel con la foto del político y el texto en letras naranjas, pero su simplicidad es máxima y la falta de elaboración se aprecia en el hecho de que la imagen de la cara del político queda cortada en todos los tuits, con lo que el formato se modifica y reajusta para todos los tuits que anuncian actos con participación de sus líderes. Otro modelo muy repetido es el que superpone texto a una fotografía "mitinera", que ocupa toda la imagen 

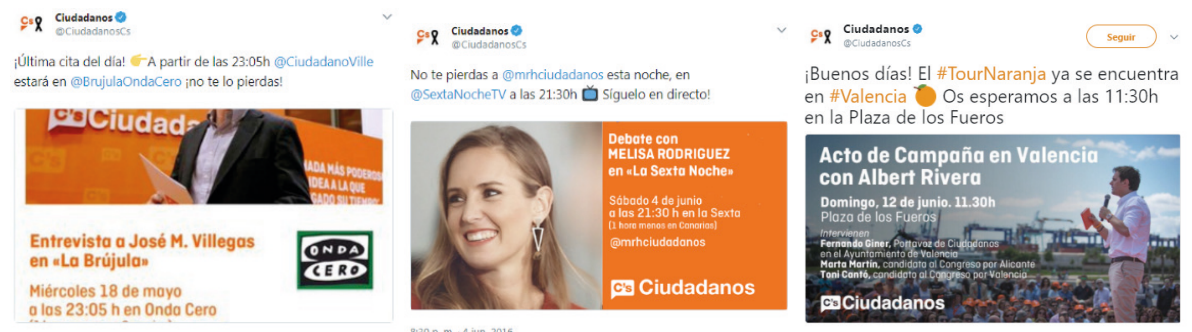

10.020 p.m. 18 may. 2015

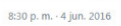

Imagen 29-31: Edición de imágenes en el perfil de Ciudadanos: el formato excesivamente grande, inadecuado para la interfaz de Twitter se sustituye por otro más ajustado, que se repite para diversos tuits de agenda; el otro modelo (dcha) superpone texto a la fotografía.

La edición de imágenes del PSOE para anunciar los eventos en que participan sus políticos mantiene homogeneidad en el formato y la tipografía, pero hay más heterogeneidad cromática; el estilo es el típico de la cartelería electoral (Checa 2013), con el rostro del político como tema protagonista.

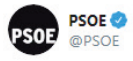

Esta noche, a partir de las 22:40h, Margarita Robles participa en el debate 4 de @antena3com. ¡No te lo pierdas!

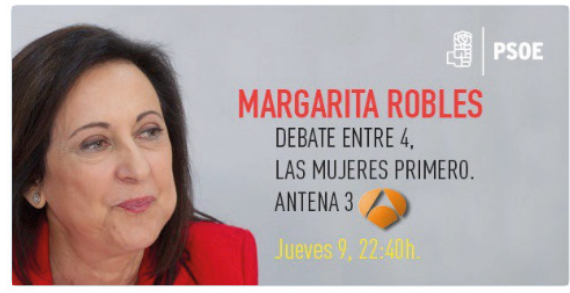

7:52 p. m. $\cdot 9$ jun. 2016

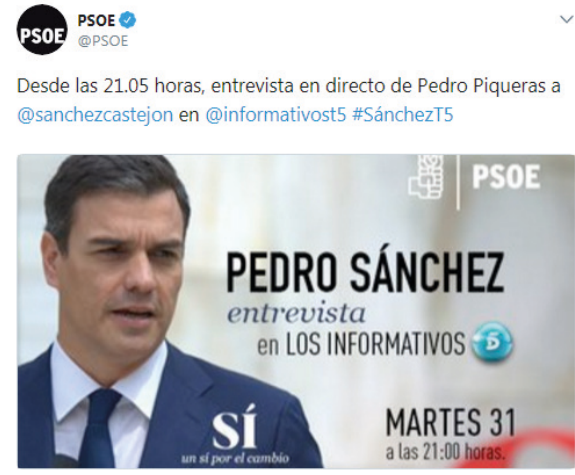

7:06 p. m. 31 may. 2016

Imagen 32-33: La cuenta del PSOE: el formato más habitual en las imágenes editadas para los tuits de agenda.

El otro uso destacado de la edición de fotografías es la superposición de texto con una cita del líder, opción que es claramente mayoritaria en el corpus; la cita puede o no coincidir con la que se incluye como texto del tuit. Con frecuencia, la labor de edición se plasma también en la calidad de las fotografías (muchas son de archivo y no proceden del acto que se retransmite). 


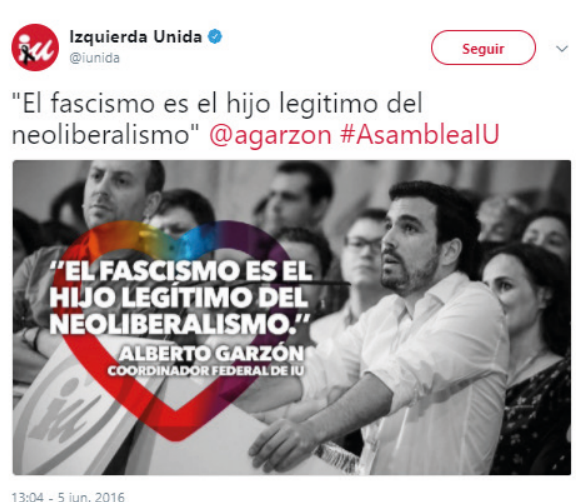

cs Ciudadanos $\bullet$

.@Albert_Rivera "Queremos ayudar no sólo a solucionar el problema político en Venezuela, también el humanitario"
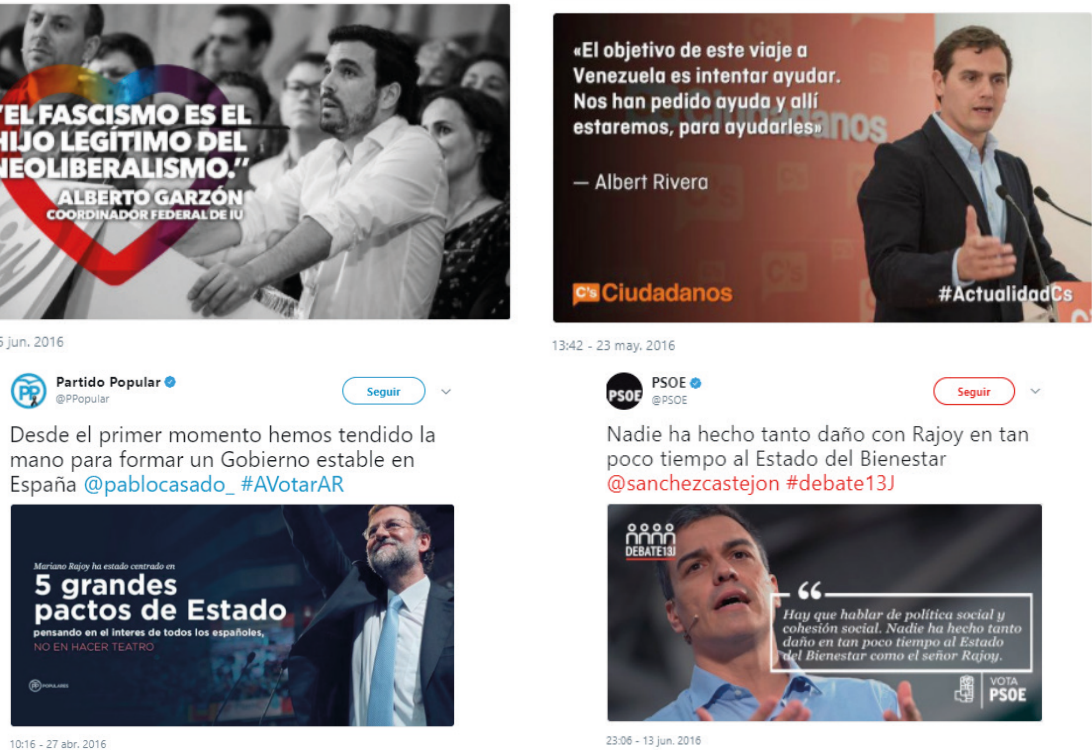

Imagen 34-37: Usos de la fotografía editada: la cita del texto del tuit se repite superpuesta a la fotografía del líder (IU), la cita de la foto complementa la del texto (Ciudadanos, PSOE), o la fotografía amplía la cita del texto introduciendo la voz del partido junto a la voz del líder (PP).

Las imágenes más elaboradas son especialmente las que transmiten la voz del partido y por tanto no se vinculan a un momento concreto; es decir, en ellas el tiempo de elaboración no coincide con el de publicación, y la fotografía no suele ser de los líderes, sino que tienen una motivación más temática/ideológica. Encontramos en las cuentas de PODEMOS, PP, PSOE un conjunto de imágenes concebidas como serie, que sí reflejan elaboración más cuidada y profesional (como mínimo en la selección de fotografías), con una estética homogénea y más sofisticada que les da identidad. Las fotos editadas y las infografías del PP revelan una apuesta mucho mayor por este tipo de imagen, y es habitual que las citas de diversos líderes se acompañen de una fotografía editada en la que aparece Mariano Rajoy con texto superpuesto en el que se mencionan presuntos logros de su gobierno o alguna cita literal suya. 


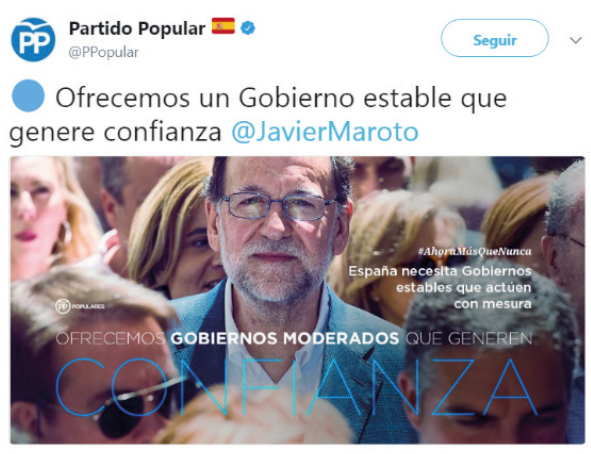

14:00 - 17 may. 2016
PP Partido Popular $=0$

¿Qué hemos hecho para luchar contra la corrupción?@pablocasado_\#L6Ncasado

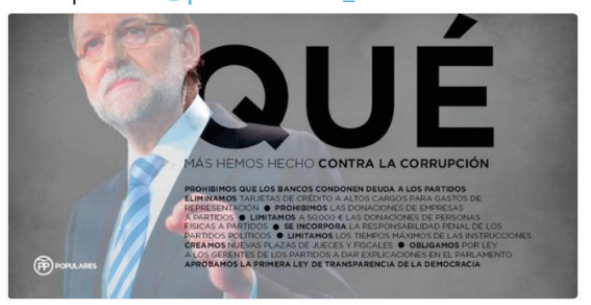

21:40 - 7 may. 2016

Imagen 38-39: Tuits de fotografía editada del PP: cita de lider que acompaña a cartel glosando los éxitos del candidato.

Estos tuits de "discurso doble" son frecuentes en los mensajes que PP y PSOE dedican la aparición de los políticos en los medios, haciendo simultáneo el discurso del líder y el discurso del partido. Por ejemplo, el seguimiento del debate televisado del 13J repite tuits en el que lo dicho por Sánchez o Rajoy se acompaña de una imagen editada; puesto que la publicación de estas imágenes es simultánea al debate, la cuenta de Twitter funciona como complemento de lo que dice cada líder. Hay, por tanto, una tarea de gestión de redes más elaborada y planificada, que como mínimo supone la elaboración de esa batería de imágenes (fotos editadas e infografías) no supeditada al estricto presente. V
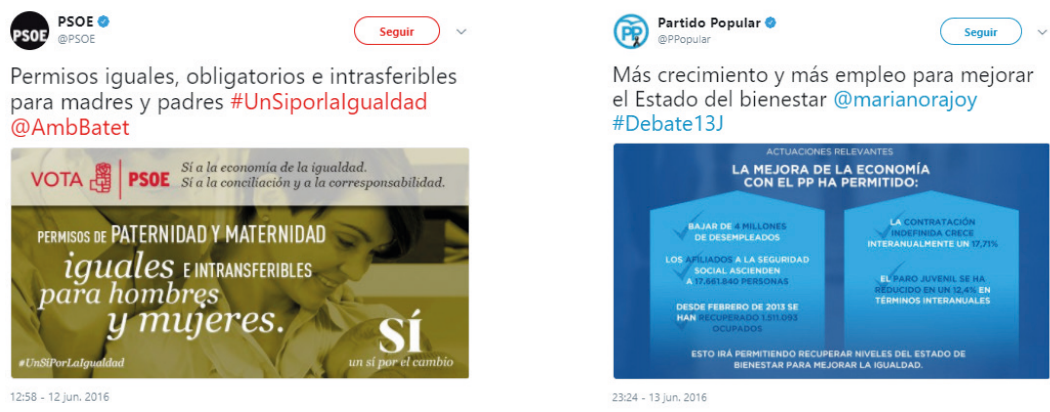

Imagen 40-41: Utilización de texto e imagen en los tuits de PP y PSOE para introducir dos lineas discursivas diferentes aunque complementarias: la voz del lider (Meritxell Batet, Mariano Rajoy) y la voz del partido. 
El PP es sin duda el partido que más rentabiliza esta posibilidad de duplicar el mensaje de cada tuit, pues gran parte de los tuits que reproducen lo dicho por uno de sus políticos se completa con una imagen que introduce la casi omnipresente voz de Mariano Rajoy o la voz genérica del partido.

Las infografías son, igualmente, imágenes que requieren algún tipo de elaboración para la utilización de imágenes, texto y datos en mensajes claros y directos. CIUDADANOS y PSOE hacen uso de este recurso para transmitir los puntos esenciales de sus programas, por lo que es frecuente el uso de actos compromisorios, aunque algunos mensajes celebran ciertos logros en autonomías donde gobierna el PSOE. En el PP encontramos varios tuits que utilizan la infografía para ofrecer una propaganda triunfalista de sus años de gobierno, con datos estadísticos o gráficos de evolución; es sin duda la cuenta que más utiliza este tipo de recurso. CIUDADANOS y el PP utilizan estas mismas infografías como base para montar vídeos breves o GIFs.

Por lo que se refiere a la calidad del diseño, las infografías del PSOE y el PP reflejan un diseño gráfico y de marca levemente más trabajado que en los otros partidos, pero ciertamente sin alcanzar niveles que revelen una apuesta decidida por este tipo de recurso comunicativo; el estilo es simple cuando no directamente infantil. Aparentemente, se trata de diseños concebidos para un consumo perecedero, sin rentabilizar su posible uso en otras plataformas y canales.
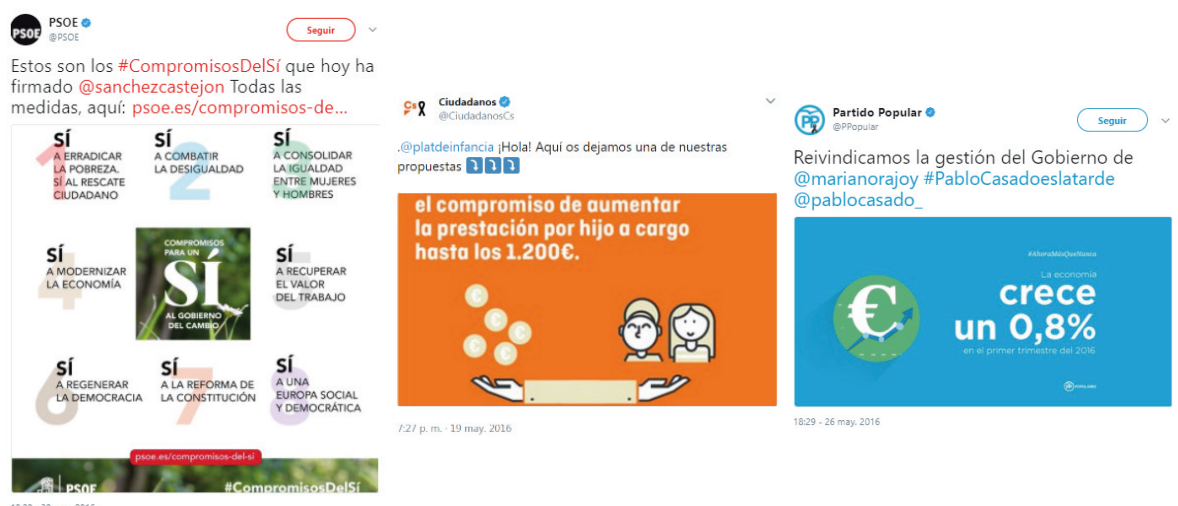

24. p. m. 19 may. 2016

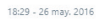

Imagen 42-44: Infografias: diseño infantil y de escasa elaboración 
En la cuenta de IU, igual que hemos visto con el texto, volvemos a encontrar en la imagen el uso de recursos para la ludificación. Las fotografías se utilizan como base para memes mediante la introducción de textos que activan el sentido humorístico. La infografía introduce datos que confirman o desmienten el texto del tuit (gráficos, tablas, mapas, rara vez de elaboración propia), pero se utiliza también con temáticas no políticas, por ejemplo en la plantilla elaborada y difundida con antelación al debate entre candidatos, destinada a marcar posibles afirmaciones de los participantes y "celebrarlas" con un chupito de bebida. Este perfil es diferente también porque utiliza imagen dibujada, a veces con estética anime.

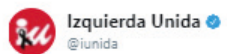

¡El \#debate13J está a punto de empezar! ¡Imprime el bingo y prepara los chupitos!

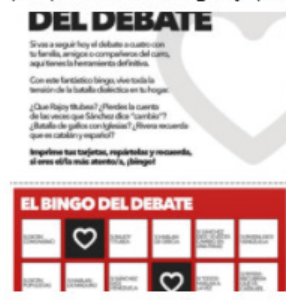

$21.21-13$ jun. 2016

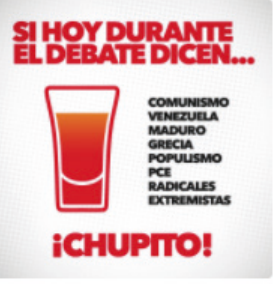

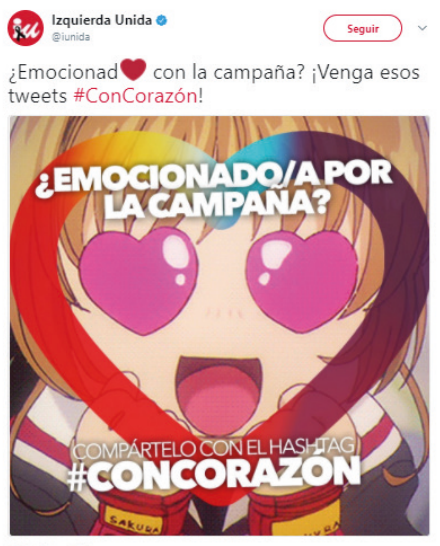

$0.36-10$ jun. 2016

Imagen 45-46: Infografía y dibujo al servicio de la espectacularización en la cuenta de IZQUIERDA UNIDA

\subsection{Tuits con vídeo y animación}

Eliminados los retuits, el corpus tiene 1408 mensajes que incluyen un vídeo. En los tres partidos encontramos cinco tipos de producto de vídeo:

1. Fragmentos de la grabación en directo del acto del líder, que según se graba se publica en una especie de retransmisión "a retazos". Los tuits van retransmitiendo breves fragmentos de los actos protagonizados por los políticos sin ser editados (solo excepcionalmente con unos fotogramas de créditos o el logo del partido). Estos fragmentos se publican inmediatamente a su grabación y su duración media es de medio minuto; algunos de ellos son autograbaciones que se hace el propio político con la cámara de su móvil o tableta. En PODEMOS predominan los vídeos de cámara fija, mientras Ciudadanos, PSOE y el PP pu- 
blican casi siempre vídeos con más de una cámara, a través de la app de vídeos cortos snappy.tv, vídeos que muchas veces alojan en el canal propio de youtube. En este grupo de vídeos "de directos" se incluyen otros de mayor duración, realizados por medio de Periscope u otras plataformas de streaming. La de IU es la cuenta más aficionada a los vídeos largos, algunos de más de 3 horas, alojados en su canal en youtube.

2. Vídeos que también son la grabación de actos "en directo", pero que reflejan algún tipo de mínima tarea de edición (plano/contraplano, cortes, créditos superpuestos...).

3. Cortes de vídeos de alguna comparecencia de los políticos en medios de comunicación. No hay podcasts, las apariciones en radio se filman y publican como vídeo.

4. Vídeos guionizados y con edición/producción, que entran dentro de la categoría de spot político, una mínima parte de los cuales son ficcionalizados y no tienen como protagonistas a los líderes de cada partido.

5. Además, hay vídeos en formato GIF (Graphic Interchange Format).

Los actos que se graban y publican son los grandes actos de campaña, normalmente en espacios amplios y abiertos, pero también otro tipo de situaciones. Por ejemplo, en PODEMOS e IZQUIERDA UNIDA hay bastantes grabaciones del corrillo de conversación que mantienen los distintos líderes antes o después del acto en cuestión, una especie de "entre bambalinas" que IU lleva al máximo con su serie \#GarzónOnTheRoad. En el PP son especialmente frecuentes las comparecencias en primer plano, sin datos claros de contextualización (solo el logo del partido en la pared o en el atril), que parecen haber sido grabadas ad hoc en la sede del partido, más que proceder de intervenciones reales en medios, o de actos electorales. En todo caso, predominan los espacios cerrados. CIUDADANOS ofrece también vídeos de pequeñas reuniones en habitaciones cerradas, sentados en círculo unos cuantos, hablando casi siempre el líder Albert Rivera.

PSOE es el partido que más usa el vídeo; como PP y Ciudadanos, recurre a la app snappy.tv para las retransmisiones de "directos", incluso en el caso de actos televisados; la gran mayoría de estas grabaciones son alojadas en el canal de youtube del partido. En ocasiones, el acto completo se retransmite en directo por streaming de la cuenta de youtube, y además se tuitean pequeños fragmentos del mismo encuadrados por la cita concreta del líder, y acordes a las diversas etiquetas, \#UnSíPorLaCiencia, \#UnSíPorLaIgualdad, \#UnSíPorElCambio, \#CompromisosDelSí. 


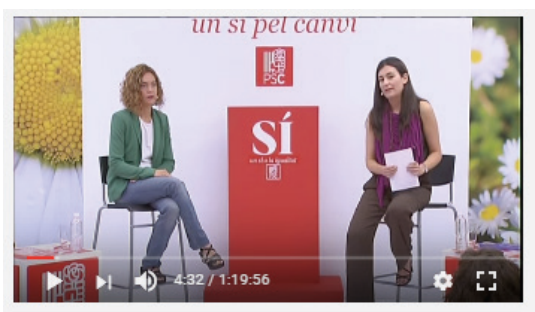

Meritxell Batet participa en un acto sectorial de igualdad en Barcelona
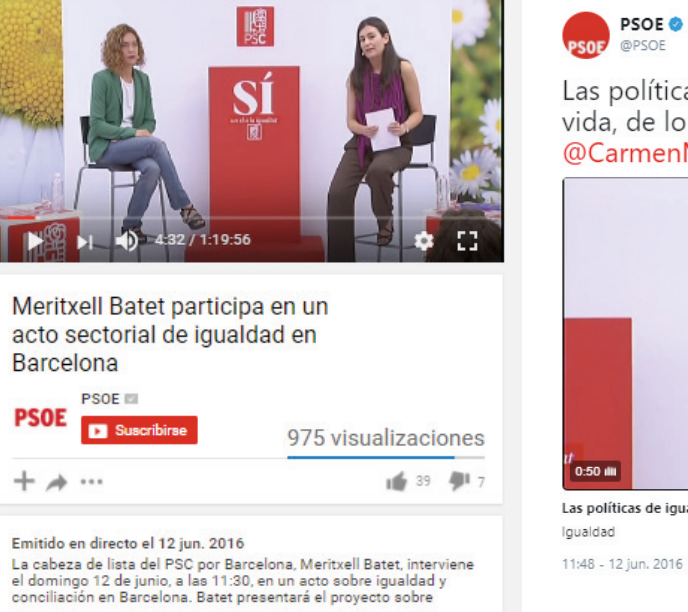

Las políticas de igualdad son políticas de vida, de lo cotidiano, del día a día @CarmenMonton \#UnSíPorLalgualdad

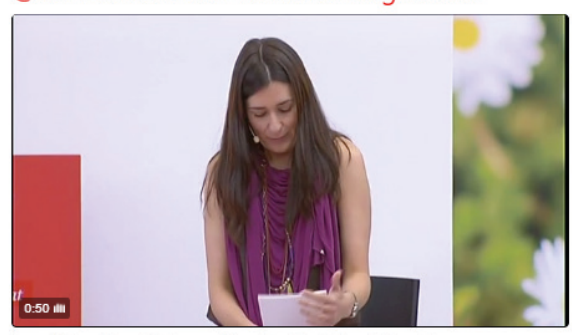

Las políticas de igualdad son políticas de vida, de lo cotidiano, de... Igualdad

$11: 48-12$ jun, 2016

Imagen 47-48: A la izquierda, recorte de la cuenta de youtube del PSOE donde se recoge el vídeo completo de un acto electoral, iniciado a las 11.30 del 12 de junio; a la derecha, uno de los tuits de retransmisión del mismo, publicado a las 11:48h.

IU edita una serie de vídeos, \#GarzónOnTheRoad, a modo de diario de campaña, que llevan firma de La Cueva Productions. Los "directos" en youtube se emiten con la edición mínima de poner el logo y los créditos de quién habla, cuándo y en qué foro (Parlamento Europeo, Asamblea IU). Es sin duda la cuenta que más uso hace de los GIFs y los vídeos de canciones o películas de youtube, de nuevo al servicio del humor y la espectacularización, incluyendo versiones paródicas de los spots de otros partidos.

También son frecuentes las ediciones de vídeo apoyadas en imagen grabada (no tanto en la confección de vídeos mediante acumulación de diapositivas con infografías). Igual que IU elabora la serie de \#GarzónOnTheRoad, el PSOE cuenta con una serie de vídeos en formato selfie de una chica a la que llaman "nuestra youtuber", pero escasamente desarrollada.

\subsection{Tuits con enlaces}

Una modalidad específica de estructura del tuit es la que incorpora texto escrito más un hipervínculo. Cuando se publica una dirección de internet en la red social, no es el usuario quien decide cómo se visualizará; lo habitual es que la interfaz ofrezca un recuadro visual del enlace en cuestión, si bien hay ocasiones en que el tuit se publica como tuit de solo texto. Igualmente, cuando se publica en Twitter una 
página web automáticamente, a partir del botón de compartir incorporado (por ejemplo, cualquier texto de la web de un medio de comunicación), también es normal que el texto del tuit venga dado por defecto.

Por tanto, la opción semiótica que realmente elige el gestor de la cuenta de partido es la de publicar un enlace, y los elementos textuales y visuales que lo complementan no pueden atribuirse a su intención directa.
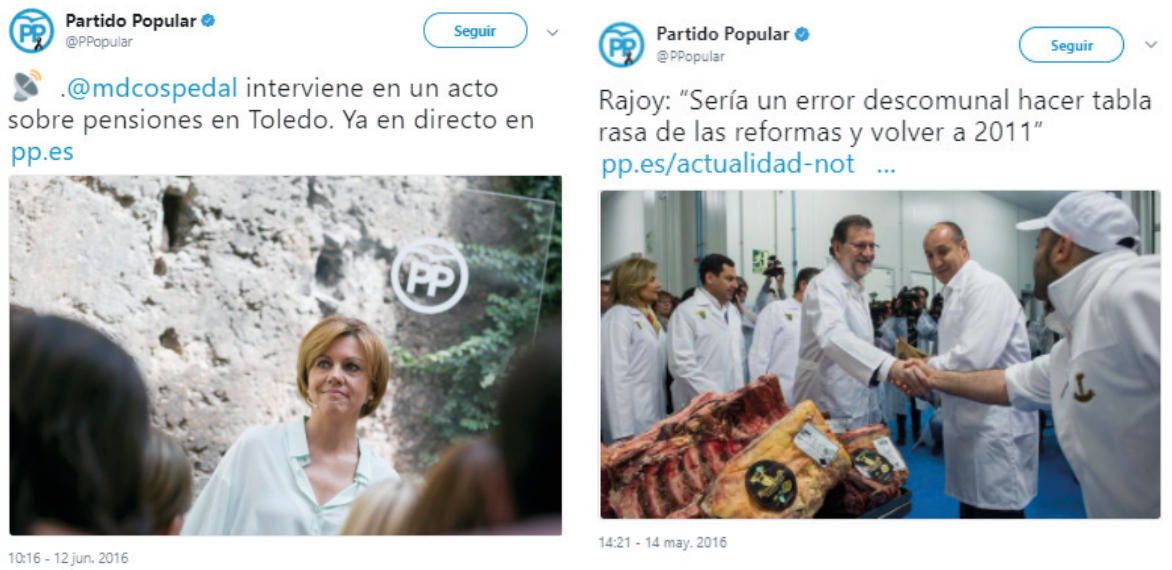

Imagen 49-50: Diferentes grados de elaboración en tuits del PP que incluyen el enlace a la web del partido: enlace
genérico o enlace especifico.

\subsection{Las claves del éxito}

Tal y como señala Usher (2016), los comandos codificados de las redes sociales se orientan especialmente a la conformidad y la coincidencia; a diferencia de Facebook, Twitter solo presenta como acción evaluativa la opción de "me gusta". Un usuario puede comentar cierto mensaje, retuitearlo (lo que no siempre indica conformidad) o marcarlo como favorito/me gusta. La finalidad es siempre la propagación del mensaje con cualquiera de estas tres posibles reacciones; la crítica incide también en el aumento de visibilidad.

¿Cuáles son los tuits del corpus con mayor número de retuits y marcas de favorito? Si atendemos a nuestros datos, vemos que los dos tuits propios más difundidos,

${ }^{7}$ Obsérvese que en el momento de redactar este texto y realizar la captura de pantalla, el número de retuits ha disminuido notablemente; esta circunstancia es habitual en el corpus, tanto de aumento como de disminución de marcas (RT y FAV). Los datos que manejamos son los del momento de descarga del corpus, la madrugada del 14 de junio de 2016. 
con 8911 y 8115 retuits, son del Partido Popular y de IZQUIERDA UNIDA; estos dos son también los tuits con más marcas de favoritos (6674 la foto de IU y 5794 el vídeo del PP):
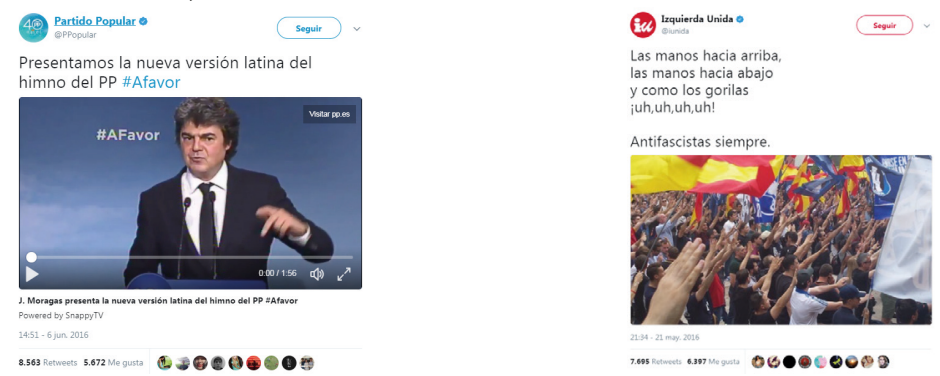

Imagen 51-52: Los dos tuits más tuiteados del corpus son mensajes que se alinean clarísimamente con la espectacularizacion de la política.

El rasgo compartido por los mensajes más exitosos no apunta a la estructura semiótica del mensaje, sino al tono; se difunden especialmente los mensajes de ilocutividad expresiva, especialmente cuando se trata de una expresividad negativa (sarcasmo, ataques, críticas, frivolización). Encontramos entre los tuits con más difusión todas las posibles estructuras que hemos señalado, incluyendo también mensajes de solo texto (7390 retuits el tuit de Rivera difundido por Ciudadanos, y 6002 el tuit de Garzón publicado por IZQUIERDA UNIDA). Como vemos, los dos retuits más difundidos son mensajes moralistas de condena:

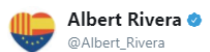

Silbar a cualquier himno que represente oficialmente a millones de ciudadanos, no es libertad de expresión,es falta de respeto y de educación

10:09 - 23 may. 2016

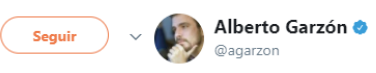

Mi apoyo al entorno de las víctimas de Orlando y de las dos mujeres asesinadas en 24 horas. Víctimas de la misma lacra: el heteropatriarcado

17:57 - 12 jun. 2016

Imagen 53-54: Los dos retuits más difundidos son tuits de cita que pertenecen a cuentas de lideres del partido: Albert Rivera y Alberto Garzón.

No cabe, por tanto, establecer una clara asociación entre impacto del tuit y estructura semiótica, aunque las plataformas de redes sociales hayan insistido en que los usuarios prestan más atención a los mensajes con imagen y, sobre todo, con vídeo. Estas afirmaciones impulsaron a los medios de comunicación a incrementar el uso del vídeo y del vídeo en directo en sus publicaciones, pero más tarde (Bell 2016) 
Zuckerberg tuvo que reconocer que había falseado los datos de impacto del vídeo en directo.

\section{LA UNIFORMIDAD DE LOS CINCO PARTIDOS}

Aunque ya vimos que los tuits con imagen en todas las cuentas suponen mayor proporción que los textos sin apoyo icónico, en este apartado consideramos por separado los seis tipos básicos de estructura semiótica, a fin de analizar la predilección de cada cuenta por uno u otro tipo de imagen.

La cuenta de PODEMOS publica un 34,6\% del total de tuits con solo texto, un $7,5 \%$ de tuits con vídeos, y un $41,3 \%$ de tuits con texto e imagen; de estos últimos, el más usual es, con diferencia, el que utiliza fotografías, si bien el partido morado hace también un uso notable de la infografía de valor pedagógico, aleccionador.
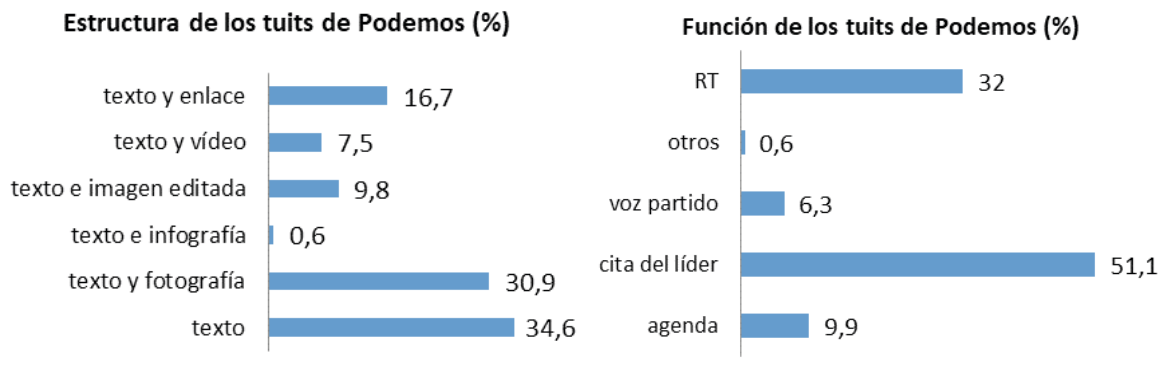

Gráfico 5: Predominios en la cuenta de PODEMOS: tuits de texto y de texto y fotografía; función de cita.

Si tenemos en cuenta todos los tipos de tuit y la funcionalidad básica de la cuenta, vemos que se dedican 318 mensajes a anunciar la agenda de actos (un 9,9\% de los tuits) y 1634 a citar las palabras de los líderes, sobre todo de Pablo Iglesias (860 menciones). Los mensajes que difunden la que cabría considerar voz general del partido son $202(6,3 \%)$.

Lo característico de la cuenta de CIUDADANOS es su concepción exclusiva del perfil de Twitter como altavoz de los líderes, con un amplísimo protagonismo de Albert Rivera, al que se dedican un 55,5\% de los tuits, ya sea como sujeto emisor 
(tuits de cita y retuits) o como protagonista de la política (tuits de agenda). Sin embargo, no hay mensajes en los que quepa reconocer una "voz de partido", Twitter se utiliza sólo como eco de los mensajes externos a la red. Un $14 \%$ de los retuits son, además, retuits de la cuenta de Albert Rivera.

\section{Estructura de los tuits de Ciudadanos}

(\%)

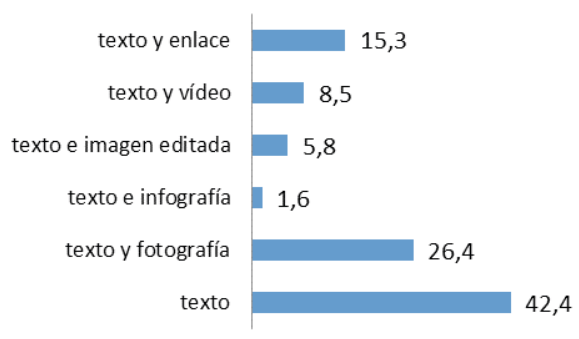

Función de los tuits de Podemos (\%)

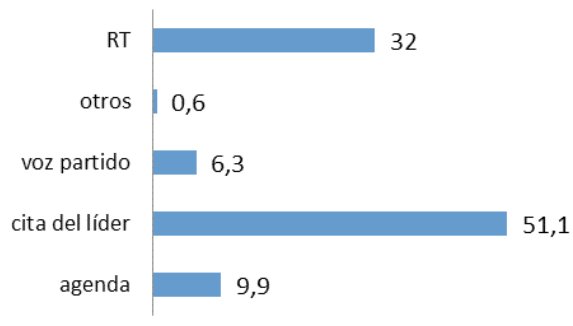

Gráfico 6: Predominios en la cuenta de Ciudadanos: tuits de texto y de texto y fotografia; función predominante de cita de lideres del partido.

La cuenta del PP plantea muchos de sus mensajes como respuesta a una pregunta que formula en el texto del tuit, y destaca también por la frecuencia con la que enlaza a su propia web de partido y usa los eslóganes de campaña a modo de hashtags. Muchas de las citas de los líderes se introducen sin comillas, pero esta sigue siendo la función predominante en el uso de Twitter: reproducir citas de los líderes políticos y dar cuenta de sus agendas electorales.

\section{Estructura de los tuits del PP (\%)}

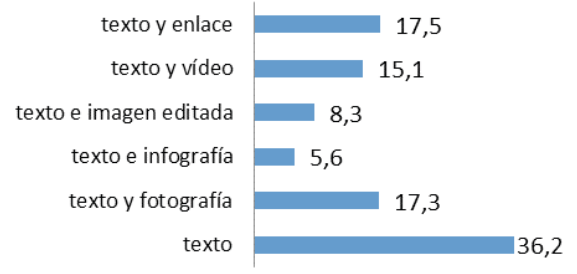

Funciones de los tuits del PP (\%)

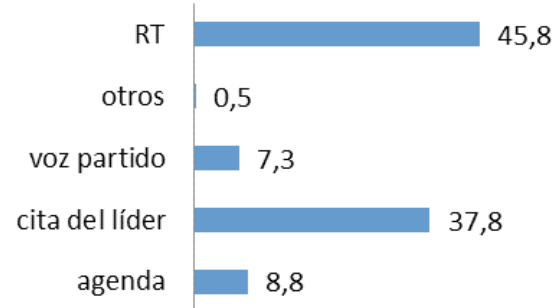

Gráfico 7: Predominios en la cuenta del PP: los tuits de texto son los más frecuentes; destacadas la función de retuit y cita. 
Como ocurre con la cuenta de Ciudadanos, gran parte de los retuits del PP (un $21 \%$ ) se concentra en la cuenta personal de Mariano Rajoy, lo que refuerza aún más esta función subordinada, ecoica.

El PSOE también rentabiliza los eslóganes de campaña en el uso de etiquetas, como ya hemos visto, para introducir en los mensajes la voz del partido. El rasgo más destacable en el uso del perfil de la red social es precisamente su concepción como cuenta del partido, que no solo traslada mensajes de líderes concretos, de ahí que sea el perfil que más tuits dedica a esta función de difusión del programa ideológico (13,2\%). Como ocurre con el PP, hay también bastantes tuits que enlazan a la web propia para ampliar información sobre las propuestas programáticas. Lo más destacado desde el punto de vista de la estructura semiótica es que se trata de la cuenta que más utiliza el vídeo $(19,1 \%)$.

Estructura de los tuits del PSOE (\%)

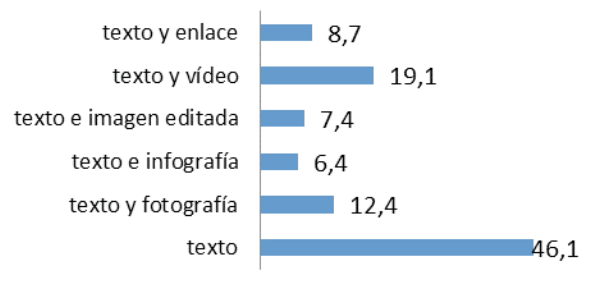

\section{Función de los tuits del PSOE (\%)}

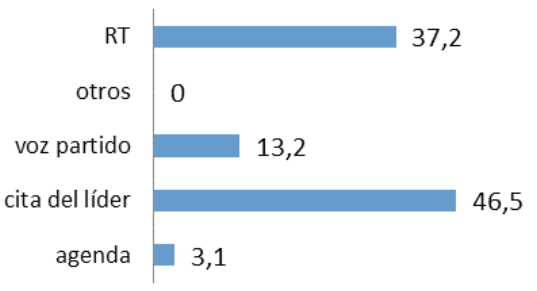

Gráfico 8: Predominios en la cuenta del PSOE: tuits de texto y vídeo; función de cita.

Por último, la cuenta de IZQUIERDA UNIDA llama la atención por la gran cantidad de tuits que se dedican a las funciones de frivolización y ludificacion como estrategia apelativa para el seguidor:

\section{Estructura de los tuits de IU (\%)}

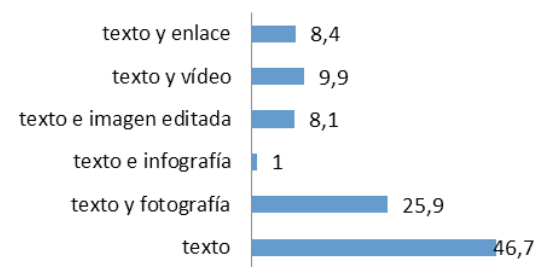

Funciones de los tuits de IU (\%)

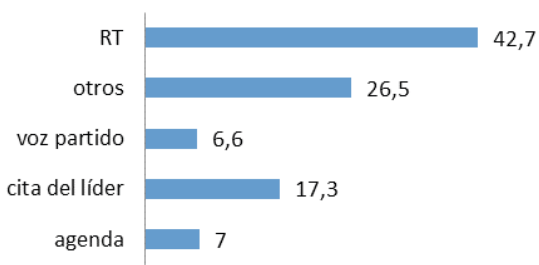

Gráfico 9: Predominios en la cuenta de IU: tuits de texto, función de RT; destaca la cantidad de tuits con "otras" funciones. 
Como puede verse, la utilización de la cuenta de partido como cuenta ecoica se reduce al mínimo del corpus (un 17,3\% de los tuits, frente al máximo del 51,5\% en PODEMOS). Ya hemos señalado que se trata de la cuenta de partido más coral, si bien el personalismo en torno a la figura de Alberto Garzón se explota de otras maneras, por ejemplo convirtiéndolo en protagonista de los mensajes, aunque sean de temática no política. Esto se explica con otro rasgo característico del perfil de IU, y es el protagonismo del equipo community manager de la cuenta, es decir, "La cueva”. Mientras en el resto de partidos esta figura es invisible, en IZQUIERDA UNIDA se insiste con frecuencia en el papel mediatizador del equipo responsable de la comunicación en redes.

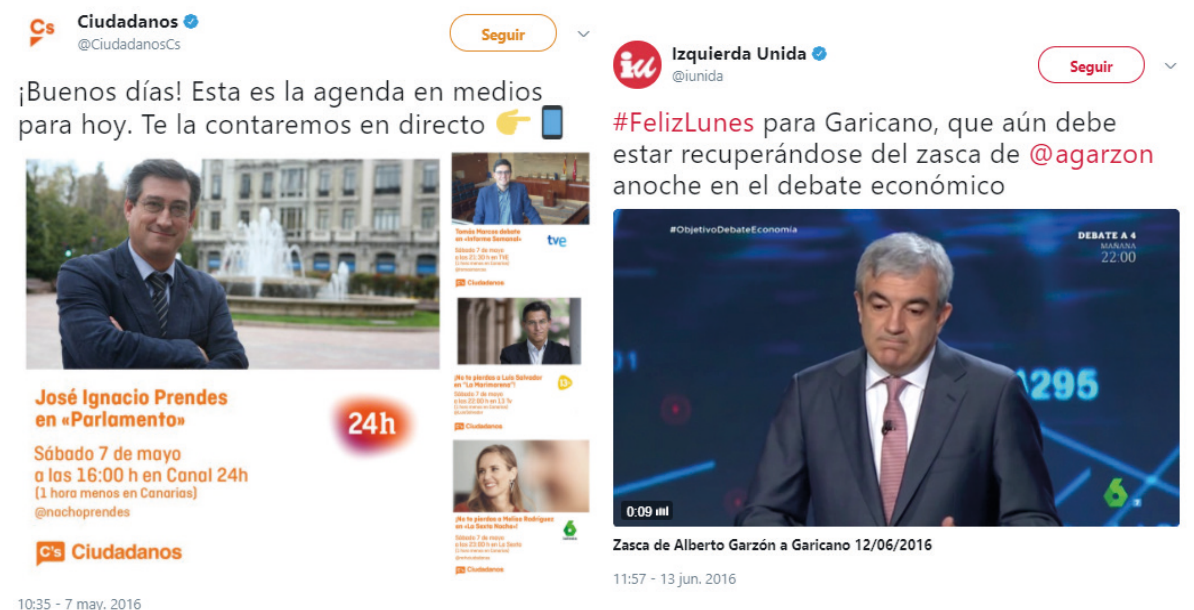

\footnotetext{
Imagen 55-56: Emergencia de los gestores del perfil como sujetos de la enunciación: mientras la cuenta de CIUDA$D A N O S$ (y demás partidos) destaca por la invisibilidad de los CM, la cuenta de IU destaca por el protagonismo intencionado de los CM en el encuadre de los tuits.
}

Como hemos avanzado, en este aspecto la cuenta de IU es una excepción. Esta cuenta destaca porque registra mucha mayor presencia de los sujetos de la enunciación; los gestores del perfil, autodesignados como "La cueva", emergen como emisores en muchos mensajes, ya sea por el tono lúdico o de parodia, ya sea porque los textos de presentación de los contenidos visuales van más allá de la simple descripción y son también una toma de partido, normalmente de tono desenfadado cuando no claramente frívolo. Destaca igualmente la frecuencia con que los tuits dan protagonismo a políticos de los demás partidos, especialmente para el ataque sarcástico. Hay varios tuits que son exclusivamente autorreferenciales, y muchísimos que se dedican a dialogar con seguidores sobre la propia actividad de gestión de la cuenta y sobre 
bromas generadas por los ataques a otros partidos. De ahí que haya muchos menos tuits de cita directa y se prefiera la glosa, que permite encuadrar el mensaje de los líderes y orientar explícitamente la interpretación.

Se diría que en muchas ocasiones la cuenta no funciona como un perfil del partido político, sino más bien como un perfil del equipo de comunicación, marcado por la búsqueda de complicidades en clave humorística y paródica, que en realidad no hablan de política, sino que apelan al "tú" del seguidor. El tono irreverente, incluso en los tuits que hablan de política, es difícilmente aceptable para una institución, como no deja de ser un partido político. En esta estrategia de frivolización el léxico marcado impone a la cuenta un sesgo de edad que puede tener efectos excluyentes para ciertos seguidores: "Mirad@ahorapodemos, dice@PoletikaORGquenuestros programas son los más molones" (Tuit del 08.06.16), "Tweet para el fandom: si nos echáis un cable en la campaña, genial. Si preferis no meteros, sin problema. Haced lo que estiméis oportuno" (Tuit del 23.05.16).

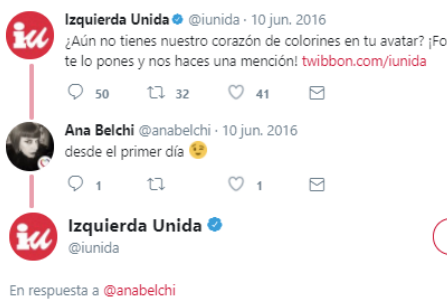

ahí va ese follow que te debíamos 1::33 - 11 jun. 2016

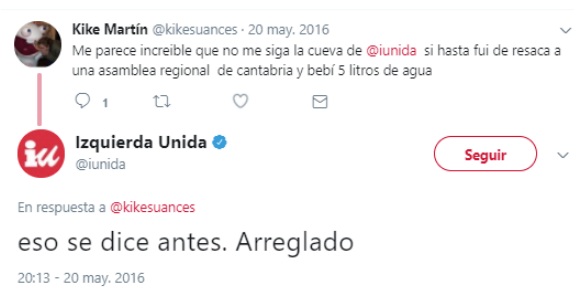

Seguir $\approx$

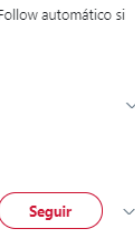

20:13 - 20 may. 2016

Imagen 57-58: Ejemplos de tuits de la cuenta de IU que responden a comentarios y apelan al "tú" de los seguidores, individualizándolos.

Este rasgo se ajusta con las conclusiones de Gallardo (2017) sobre la desideologización de los mensajes de los seguidores de Twitter. Su estudio analiza los tuits reactivos de los seguidores, tanto a los mismos tuits de partidos que analizamos en este trabajo, como a los mensajes publicados en las cuentas de los correspondientes líderes (Garzón, Iglesias, Rajoy, Rivera, Sánchez), y comprueba que el 83,3\% de los tuits de seguidores de IU y el 86,7\% de los tuits de los seguidores de Alberto Garzón son tuits de tema no político. La complicidad con los seguidores/votantes se busca por otros cauces, de manera que la coincidencia ideológica se da por supuesta y es la base para el intercambio de bromas y la interacción directa con el "tú" votante. 


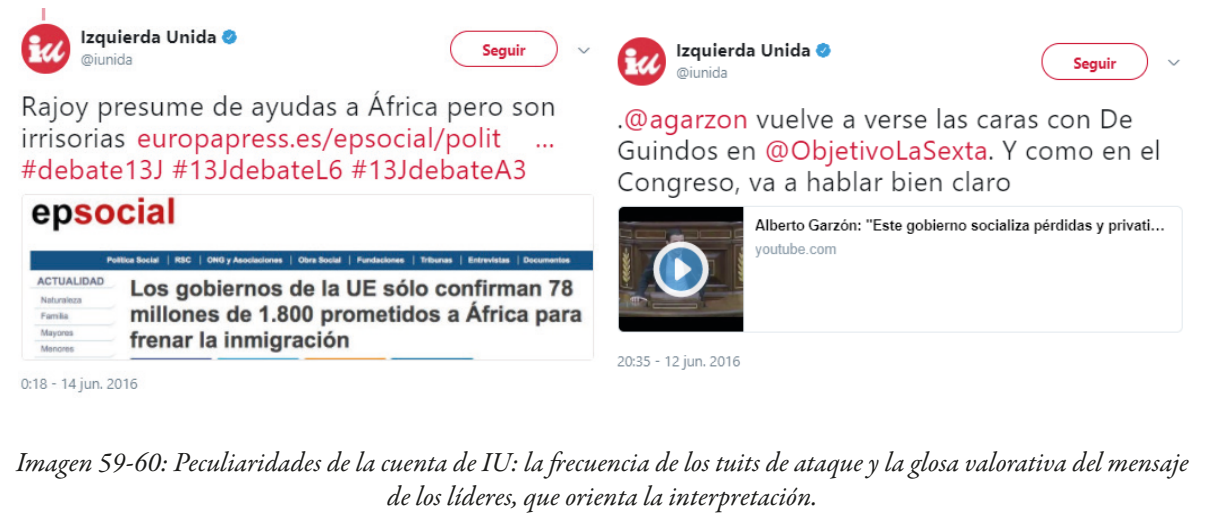

\section{CONCLUSIONES}

Hemos analizado el uso de Twitter por parte de cinco partidos políticos españoles presentes en la campaña electoral de 2016, y la conclusión fundamental es que estas cuentas son absolutamente ecoicas respecto a las cuentas de los líderes políticos, muy especialmente las de los respectivos candidatos (y Garzón, en el caso de IU). Si tenemos en cuenta exclusivamente la aparición del candidato en los tuits del partido vemos que prácticamente en uno de cada dos tuits se lo incluye, ya sea mediante un retuit directo de su cuenta, mediante la mención de su alias en Twitter, o mediante la alusión explícita como protagonista del mensaje o en el hashtag.

Gráfico 10: Aparición del candidato del partido en los tuits publicados: retuits, menciones y alusiones.

Los partidos políticos españoles están presentes en las redes sociales, parecería inconcebible lo contrario, pero sus cuentas en Twitter no evidencian un uso realmente institucional, sino que se pone al servicio del personalismo de la política, cediendo la voz sobre todo a los líderes del partido y, más específicamente, a los candidatos. Este desajuste apunta a una profesionalización baja del rol de gestor de redes sociales, pues los partidos no están usando estos canales como fuente emisora real, primaria, sino subordinada a la voz de los líderes.

Si intentamos cruzar las dos clasificaciones que hemos propuesto, funcionalidad y estructura, de nuevo el personalismo aparece como rasgo esencial, y resulta posible detectar leves tendencias en el uso de imagen para los diferentes tipos de tuit que hemos señalado: para los tuis de agenda que anuncian actos de campaña predomina el uso de la fotografía editada, mientras que hay cierta especialización de la infografía para transmitir la voz de partido, siendo ambos tipos los menos representados. 
Tampoco cabe señalar para estas cuentas de partido marcas especiales que las individualicen. Si atendemos a las características de los tuits que publican, podemos señalar solo leves matices, por ejemplo que PODEMOS es el partido que más recurre a la fotografía testimonial, en directo; que el PSOE destaca por ser el que publica más vídeos y menos fotografías-testigo, y el que más tuits institucionales publica, es decir, con la voz del partido; o que el PP es el que publica más tuits con enlaces web y el que más retuitea. Sin embargo, es mucho más lo que las cuentas tienen en común, que nos permite hablar de una clara (y anodina) uniformidad, por ejemplo en el absoluto predominio de los tuits de cita en todas las cuentas. La única nota realmente destacada la encontramos en la cuenta de IZQUIERDA UNIDA, que junto al personalismo recurre a otro de los rasgos con los que caracterizamos la pseudopolítica de las redes sociales (Gallardo y Enguix 2016): la espectacularización frívola, que se utiliza como medio de identificación con el seguidor.

En definitiva, las cuestiones que nos planteábamos en esta investigación nos llevan a concluir que se aprecia un uso equilibrado de la imagen y el texto en los mensajes de Twitter, pero predomina la imagen fija sobre el vídeo. La relación entre ambos recursos es complementaria, y ocasionalmente se rentabiliza hasta el punto de introducir dos líneas discursivas diferentes. Por último, un análisis atento a las funciones que realizan los tuits permite afirmar que la gestión de las cuentas de Twitter no revela un especial cuidado por parte de los partidos políticos; por el contrario, son cuentas subordinadas, sin apenas iniciativa comunicativa, que funcionan al servicio del líder político, ya sea redifundiendo sus mensajes o publicando su agenda de campaña. Los perfiles de Twitter apenas se dedican a difundir la voz del partido.

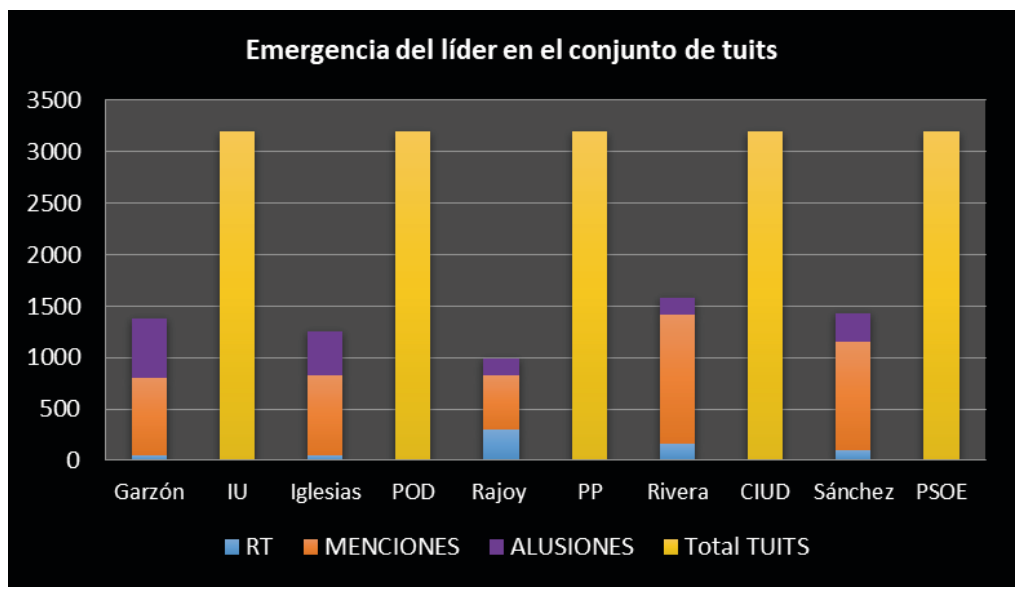




\section{REFERENCIAS BIBLIOGRÁFICAS}

ABEJÓN, Paloma et al. (2017): "El uso de webs, Facebook y Twitter en la comunicación electoral española de 2015: una mirada impresionista",en J.L. Dader y E. Campos (Coords): La buisqueda digital del voto. Cibercampañas electorales en España 2015-2016. València: Tirant Lo Blanch, 75-140.

ABRIL, Gonzalo (2013): Cultura visual, de la semiótica a la politica, Madrid: Plaza y Valdés.

AUTY, Caroline \& COWEN, Alison (2001): "Political parties on the Net - 4 years closer to cyber-utopia?” en Aslib Proceedings 53.9, pp.340-352. http:// www.emeraldinsight.com/doi/pdfplus/10.1108/EUM0000000007066

BLUMENTHAL, Sidney (1980): The Permanent Campaign: Inside the World of Elite Political Operatives, Boston, Beacon.

CASTELLS, Manuel (2008): Castells, Manuel (2008): “Comunicación, poder y contrapoder en la sociedad red (I). Los medios y la política", TELOS 74, https://telos.fundaciontelefonica.com/telos/articuloautorinvitado.asp@ idarticulo $=1 \& \mathrm{rev}=74 . \mathrm{htm}$

CHECA GODOY, Antonio (2013): El cartel. Dos siglos de publicidad y propaganda. Sevilla: Advook Editorial.

DADER, José Luis (2017): “Campañas políticas 'online’: la realidad española frente al horizonte internacional del 'tecnocabildeo", en J.L. Dader y E. Campos (Coords): La búsqueda digital del voto. Cibercampañas electorales en España 2015-2016. València: Tirant Lo Blanch, 11-73.

ENGUIX OLIVER, Salvador (2017): "Impacto político e informativo de las redes sociales: esferas de actuación y comparación con los medios" en Análisi. Quaderns de Comunicació i Cultura, 56, 71-85. http://analisi.cat/article/ view/n56-enguix

GALLARDO PAÚLS, Beatriz \& ENGUIX OLIVER, Salvador (2016): Pseudopolitica. El discurso politico en las redes sociales. Valencia: Universitat.

GALLARDO PAÚLS, Beatriz (2014): Usos politicos del lenguaje. Un discurso paradójico. Barcelona: Anthropos/Siglo XXI.

GALLARDO PAÚLS, Beatriz (2016): "Programas de tertulia política en Twitter: un modelo neurocomunicativo de análisis del discurso" en CLAC. Círculo de Lingüistica Aplicada a la Comunicación, vol 66, 86-147. http://revistas. ucm.es/index.php/CLAC/article/view/52770

GALLARDO PAÚLS, Beatriz (2017): "Pseudopolítica en la red: indicadores discursivos de desideologización en Twitter”, Pragmalingüística 25, 189-210. http:/ / revistas.uca.es/index.php/pragma/article/viewFile/3393/3767

GALLARDO PAÚLS, Beatriz (2018): "Politicians in Twitter: discursive features of personalization in Pseudopolitics", en Populismi, nuove destre, nuovi par- 
titi: quali discorsi politici in Europa?, Università di Pisa.

GARCÍA-AVILÉS, José Alberto \& ARIAS, Félix (2016): “Géneros periodísticos en los formatos visuales de Twitter: uma propuesta de tipologia”. Textual \& Visual Media 9, 101-132. http://textualvisualmedia.com/images/revistas/9/articulos/generospe.pdf

JOHNSON-CARTEE, Karen S. (2004): News narratives and news framing: Constructing political reality, Rowman \& Littlefield Publishers

LAKOFF, George (2004): No pienses en un elefante. Madrid: UCM, 2007. Trad. de Magdalena Mora.

LAKOFF, George (2006): Puntos de reflexión. Manual del progressista. Barcelona: Eds. Península, 2008. Trad. de Judith Wells.

LÓPEZ RABADÁN, Pablo; LÓPEZ-MERI, Amparo; DOMÉNECH-FABREGAT, Hugo (2016): "La imagen política en Twitter. Usos y estrategias de los partidos políticos españoles”, Index.Comunicación, 6, 165-195.

MACKEY, Stephen (2016): "Persona - an old public relations problem?" en Persona Studies 2.1 (2016): 84-96. https://ojs.deakin.edu.au/index.php/ps/ article/view/533

MARLAND, Alex (2012): "Political Photography, Journalism and Framing in the Digital Age" en Press/Politics 17.2, http://journals.sagepub.com/doi/ pdf/10.1177/1940161211433838

NEEDHAM, Catherine (2005): "Brand leaders: Clinton, Blair and the limitations of the permanent campaign”, en Political studies, no 53 (2), pp. 343-361.

PELLISSER, Nel.lo; VILLAR, Paz \& ENGUIX, Salvador (2017): "El vídeo electoral: nuevas estrategias y mensajes en Twitter". VI Congreso Internacional de Investigadores Audiovisuales. Tecnología y Contenidos Digitales. Universidad Camilo José Cela. 27 y 28 abril 2017.

PRATKANIS, Anthony \& ARONSON, Eliot (1992): Age of propaganda. New York: W.H. Freeman and Company.

RUIZ DEL OLMO, Francisco Javier \& BUSTOS DÍAZ, Javier (2016): “Del tweet a la fotografía, la evolución de la comunicación política en Twitter hacia la imagen. El caso del Debate del Estado de la Nación en España (2015)" en Revista Latina de Comunicación Social, 71, pp. 108 a 123. http:/ / www.revistalatinacs.org/071/paper/1086/06es.html

USHER, Bethany (2016): "ME, YOU, And US: Constructing political persona on social networks during the 2015 UK General Election" en Persona Studies; 2 (2), http://tees.openrepository.com/tees/bitstream/10149/620899/2/620899.pdf

Fecha de recepción: 3 de julio de 2018 Fecha de aceptación: 27 de septiembre de 2018 
